\title{
Functional food science and behaviour and psychological functions
}

\author{
F. Bellisle ${ }^{1 *}$, J. E. Blundell ${ }^{2}$, L. Dye ${ }^{2}$, M. Fantino ${ }^{3}$, E. Fern ${ }^{4}$, R. J. Fletcher ${ }^{5}$, J. Lambert ${ }^{6}$, M. Roberfroid ${ }^{7}$, \\ S. Specter ${ }^{1}$, J. Westenhöfer ${ }^{8}$ and M. S. Westerterp-Plantenga ${ }^{9}$ \\ ${ }^{1}$ INSERM - Unité 341 et Service de Nutrition, Hôtel-Dieu, \\ 1, Place du Parvis Notre-Dame, F-75181, Paris Cedex 04, France \\ ${ }^{2}$ PsychoBiology Group, Department of Psychology, University of Leeds, Leeds LS2 9JT, UK \\ ${ }^{3}$ Laboratoire de Physiologie, Faculté de Médecine, Université de Bourgogne, \\ 7, Boulevard Jeanne d'Arc, F-21033 Dijon Cedex, France \\ ${ }^{4}$ Nestec Ltd, Nestlé, 55, Avenue Nestlé, CH-1800 Vevey, Switzerland \\ ${ }^{5}$ Kellogg Company of Great Britain Ltd, The Kellogg Building, Talbot Road, Manchester M16 OPU, UK \\ ${ }^{6}$ Mars Confectionery, Division of Mars UK Ltd, Dundee Road, Slough SL1 4JX, UK \\ ${ }^{7}$ UCL, Ecole de Pharmacie, Tour Van Helmont, Avenue E. Mounier, 73, B-1200 Brussels, Belgium \\ ${ }^{8}$ Department of Nutrition and Home Economics, Advanced Technical College, \\ Lohbrügger Kirchstr. 65, D-21033 Hamburg, Germany \\ ${ }^{9}$ Department of Sciences, Open University of the Netherlands/Maastricht University, Postbus 2960,
} NL-6401 DL Heerlen, The Netherlands

\section{Contents}

1. Overview

2. General methodological considerations

2.1. Ensuring the reliability of food intake data $\mathrm{S} 175$

3. Functions of macronutrients in relation to appetite $\$ 175$

3.1. Overview

3.1.1. Ethnic, educational and social determinants

S175

$\mathrm{S} 175$

3.1.2. Circadian rhythms

3.2. Effects of macronutrient intake on energy intake, hunger, satiety and metabolism

3.2.1. Fat intake in relation to energy balance $\mathrm{S} 175$

3.2.2. Fat and carbohydrate intake in relation to satiety

S176

3.2.3. Relative levels of fat, carbohydrate and protein intake in relation to satiety and metabolism

S176

3.2.4. Alcohol intake and satiety

3.3. Functional properties of macronutrient substitutes

S176

3.3.1. The preload paradigm $\quad \mathrm{S} 177$

3.3.2. The issue of compensation $\quad \mathrm{S} 177$

3.3.3. Highlight: sucrose polyester $\quad \mathrm{S177}$

3.4. Modulating food intake through palatability

enhancers: the case of monosodium glutamate $\quad$ S178

4. Foods and cognitive performance $\quad \mathrm{S} 178$

4.1. Overview $\quad \mathrm{S} 178$

4.2. Performance tasks $\quad \mathrm{S} 178$

4.3. Effects of nutritional manipulations on performance

S179

4.3.1. Food v. no food first thing in the morning $\$ 179$

4.3.2. Effects at midday
4.3.3. Effects following evening meals

4.4. Influence of macronutrient ratios and individual nutrients

4.4.1. The carbohydrate-tryptophan connection $\mathrm{S} 180$

4.4.2. Dietary fat

4.4.3. Glucose

4.4.4. Dietary choline

4.4.5. Vitamins and minerals

4.4.6. Alcohol

4.5. The case of caffeine

5. Functional effects of foods on activation or sedation $\mathrm{S} 182$

5.1. Overview

5.2. Methods for assessing activation or sedation $\quad$ S182

5.2.1. Tryptophan

5.2.2. Tryptophan, tyrosine, and 'jet lag' $\mathrm{S} 183$

5.3. Carbohydrate v. protein: effects on performance $\mathrm{S} 183$

5.4. Caffeine-driven activation

S183

6. Influence of food and individual nutrients on

affective state

S183

6.1. Overview

S183

6.2. Diet-related dysphoria

S183

6.3. Central neurochemical activity and mood state

6.4. Other links between nutrition, mood and brain serotonin levels

S184

S184

7. Nutrition and endorphins $\quad$ S184

8. Safety issues $\quad \mathbf{S 1 8 5}$

8.1. Overview $\quad \mathrm{S} 185$

8.2. Tryptophan $\quad \mathrm{S} 185$

8.3. Caffeine $\mathrm{S} 185$

8.4. Macronutrient substitutes and flavour enhancers S185

Abbreviations: DHA, docosahexaenoic acid; MSG, monosodium glutamate; SPE, sucrose polyester.

*Corresponding author: Dr F. Bellisle, fax +33 1404682 48, email bellisle@imaginet.fr 
9. Hyperactivity

9.1. Overview

9.2. Hyperactivity and sugar

9.3. Hyperactivity and food additives

10. Critical assessment of the science base: identification of criteria

11. Considerations for future research
S185

S185

S185

S186

S186

S187
11.1. Appetite and satiety

11.2. Macronutrient replacers

11.3. Palatability enhancers

11.4. Cognitive performance

11.5. Pain perception

11.6. Sensitive subgroups

11.7. Time-dependent effects
S187

S187

S187

S187

S188

S188

S188

\begin{abstract}
The impact of ingesting various foods on psychological and behavioural functions is a topic of both interest and concern to the general public. In this article, the scientific literature concerning demonstrated cause-and-effect relationships is reviewed, beginning with methodological considerations specific to the quantification of particular behaviours and psychological events. The essential function of food is to satisfy hunger and the need for essential nutrients. The contributions of macronutrients to appetite and satiety are described, as well as their impact on metabolism and energy balance. Functional properties of macronutrient substitutes (highintensity sweeteners, fat replacers) and flavour enhancers are examined in relation to their contribution to hunger, satiety, and energy balance. The effects of foods and individual nutrients on the performance of diverse psychomotor tasks are studied with consideration given to the various validated quantitative tools used to assess behaviour. The effects of food components on activation, sedation, and affective states such as dysphoria are also reviewed, with special attention given to brain function and neuroactive substances such as serotonin and the endorphins. The case of hyperactivity in children is given special emphasis with reference to the potential influence of sugar and food additives. Safety issues related to food constituents and additives are discussed. Finally, a set of criteria is proposed for the evaluation and elaboration of studies in the behavioural and psychological fields, along with suggestions for future research.
\end{abstract}

\title{
Behaviour: Mental state: Mood
}

\section{Overview}

Human ingestive behaviour can be influenced by a number of factors extrinsic to physiological requirements or the nutritional value of individual dietary components. To the extent that certain foods confer additional, and sometimes unexpected, health benefits, they are, according to today's terminology, recognized as 'functional', and are of increasing scientific interest. Public attention is easily captured by claims in the popular press that behaviour is influenced by diet. However, supportive scientific evidence has generally been weak and the data often over-interpreted. At this point, what is needed are rigorously controlled laboratory and field investigations to examine the validity of an ever-increasing array of anecdotal observations.

While biological end-points can be considered universal (e.g. decrease in blood cholesterol, protection from carcinogens), behavioural and psychological end-points can often be culture-specific. Therefore, a food considered to be functional in one society can be less functional or, indeed, not even recognized as such in another. Although foods with diverse functions are known and used in a multitude of cultures throughout the world according to long-standing traditions, the present report focuses exclusively on studies involving Western populations and is limited to describing food functionality in this context.

\section{General methodological considerations}

The effects of foods and food constituents on behaviour, emotional state, and cognitive performance are typically subtle. Sensitive tests and measures are required to identify, operationalize, and measure behaviours associated with nutrient intake and to uncover causal relationships. From an experimental design standpoint, dose-response trials are indispensable to demonstrate, convincingly, true specificity. Very little can be learned regarding the quantitative effects of a taste stimulus following exposure at one single concentration. Qualitative effects also tend to change with changing stimulus concentrations, particularly with food stimuli, where both the dose (i.e. amount) and the extent of exposure are manipulated.

Interpretation of behavioural effects will necessarily be linked to the time frame of the experiment. The rate, intensity, and temporal pattern of responses are functions of experimental duration. Acute biochemical changes require immediate observation, whereas the adaptation, learning, and tolerance that can surface during chronic treatments are not likely to be apparent in short-term studies.

Outcomes also depend, not surprisingly, on the nature of the sample population. Subjects can be selected or grouped to control for a variety of factors including body size (i.e. by BMI), percentage body fat, dietary habits, weight history, food preferences, and demographics. Questionnaires and personal interviews can be used to isolate individual characteristics or to study certain subjective experiences such as desire to eat, food palatability, and general mood state. Nominal scaling methods such as rank order, fixedpoint, multidimensional, and visual analogue are frequently employed to assess hedonics and levels of hunger, appetite, and satiety (Rolls \& Hetherington, 1990). 
It should be borne in mind that physical characteristics alone are probably not a sound basis for delineating subject groups (Spitzer \& Rodin, 1981). Personal experience, as well as attitudes toward beliefs about food, also markedly influence eating behaviour (Aaron et al. 1994). If determined systematically beforehand, these might serve as criteria when treatment groups are formed (Aaron et al. 1994). Since most individuals tend to have strong beliefs about particular foods, blinding subjects to the experimental variables is necessary. This becomes more critical (and progressively more difficult) as the magnitude of dietary manipulations increases. Of course, blinding is not desirable if the subjects' cognitions and expectations are central to the questions being studied.

Which factors should be considered when characterizing subjects remains controversial; nevertheless, numerous methods are available to aid in classification, including the 'restraint scale' (Herman \& Polivy, 1980), which measures concern for dieting and weight fluctuation in general, the 'three-factor eating inventory' (Stunkard \& Messick, 1985), which measures dietary restraint, disinhibition, and hunger, and the 'eating disorders inventory' (Garner et al. 1983), which examines attitudes, beliefs, and activities associated with dysfunctional eating behaviour. In addition to physical characteristics, these criteria can be used to classify subjects with the aim of decreasing within-group variation.

Cause-effect relationships between nutrients and behaviour can and should be tested in both experimental and naturalistic settings. There is greater control in the laboratory, whereas free-living conditions tend to be more ecologically valid. Whatever the experimental strategy (direct observation $v$. verbal report, between- $v$. withinsubjects ('crossover') design) each approach carries certain strengths and certain limitations. For example, certain behaviours are normally private and not easy to observe in any setting. Direct observation offers the greatest accuracy, but is often intrusive and necessarily artificial, whereas obtaining the information by follow-up interview leaves the original behaviour intact. But while an open-ended verbal exchange offers flexibility, it introduces the risk of multiple interpretations. Using a questionnaire with a written set of fixed alternatives imposes structure, but it may prove leading and leave subjects feeling constrained and limited.

To study the relationship between nutrients and mood state, numerous standardized scales and questionnaires such as the 'profile of mood states' (McNair et al. 1971) have been developed and validated in order to score particular psychological states. Examining the relationship between selfreported mental states and objective laboratory measures of performance allows the experimenters to use objective performance as a behavioural index of nutrient effects.

\subsection{Ensuring the reliability of food intake data}

Reliable food intake data are a precondition for establishing the validity of experimental results. The standard methods of determining food intake are:

(1) indirect determination based on group consumption data, inspection of family budgets, larder inventories, and agricultural production data;

(2) estimation by recall of food consumed over the last day, week, month, or longer;

(3) measurement and recording of food intake as eaten.

Validation of food intake measurements is the main issue. Data obtained via 'dietary recall' and 'diet records' represent food intake at an individual level. The latter method requires subjects to record types and amounts of all foods consumed over a given time interval, while the former uses the subjects' report of intake over the previous $24 \mathrm{~h}$ period or the report of customary intake over the previous week or during the past year(s); i.e. a diet history. Food models, volume models, and photographs can help to recall the amounts consumed. Alternative methods include the 'double portion' technique, in which subjects have to collect, for every food item consumed, an equivalent amount for subsequent analysis, or supplying subjects with their daily food ration, measuring the quantity and quality of the food in the laboratory, and then instructing the subjects to consume only the foods provided and to return any left-overs.

Information on the quality of food consumption will be closer to the real life situation in the method of dietary recall than when food is supplied. Conversely, the quantitative method (supplying food) is more accurate than relying on dietary recall. Generally, the subject's energy intake and expenditure should be in balance, but this is very difficult, if not impossible, to check. Sources of error include poor memory, inaccurate estimation of amounts, and wishful thinking. The latter is typical of overweight people who systematically 'under-report' and underweight people (e.g. anorexics) who 'over-report' (Westerterp et al. 1992). In addition, when respondents are required to write down, weigh, or measure what they eat, they may alter their usual dietary habits to make recording easier or to hide their habits. Intermittent energy restriction, i.e. dieting, also is a significant factor in the reduced energy intake reported in overweight people (Ballard-Barbash et al. 1996) and efforts should be made to take it into account.

The length of the observation period is primarily determined by the day-to-day variability expected and the level of accuracy desired. According to Basiotis et al. (1987), to achieve a level of precision of $10 \%$ in a single individual, record-keeping must be maintained for a minimum of 4 weeks. Comparing the dietary record, dietary recall, and the double-portion technique with bomb calorimetry in males spending 1 year on an Antarctic base, Acheson et al. (1980) found that the dietary record method underestimated the energy intake by $7 \%$ on average compared with the analysis of duplicate meals by bomb calorimetry. Errors of over $20 \%$ were found in the energy intake determined by dietary recall. With respect to underreporting, Martin et al. (1996) found the correlation between reported energy intake and expenditure to be only 0.46. Body weight, BMI, height, length of time in the dietary trial, and percentage of energy from fat and carbohydrate were not significantly associated with the accuracy of reporting. Westerterp-Plantenga et al. $(1996 a, b)$ found that, after allowing for a deviation of 
approximately $10 \%$, energy intake could be estimated using a computer simulation model (Westerterp et al. 1995).

Data on energy intake have been compared with data on energy expenditure as measured by the doubly-labelled water technique, which measures energy expenditure under normal living conditions with an accuracy of 1-3\% and a precision of 2-8\%. Under-reporting, as compared with energy expenditure measured by the doubly-labelled water method, has been reported (e.g. Westerterp et al. 1992). A good match between energy intake and energy expenditure was obtained by Sjødin et al. (1994) when energy balance was examined in cross-country skiers using doubly-labelled water and dietary records. This study was performed in a training camp where the dietary records were kept by dieticians who were continuously present. Matching energy intake with energy expenditure is also possible when subjects are fed in a respiration chamber. Schrauwen et al. (1995) concluded that it takes a $3 \mathrm{~d}$ stay in the chamber in order to enable the experimenter to correctly adjust intake to expenditure.

\section{Functions of macronutrients in relation to appetite}

\subsection{Overview}

Nutrition is the basic function performed by foods, via intake behaviours. In the sense that the periodic intake of energetic substances contributes decisively to appetite and satiety in order to meet bodily needs in a continuous fashion, all foodstuffs are functional. Intake is stimulated by sensory, physiological and social cues, and satiation and satiety are the result of a cascade of cognitive, sensory, and metabolic (post-ingestive and post-absorptive) signals.

The four macronutrients, carbohydrate, protein, fat and alcohol, have clear effects on appetite, metabolism, satiation (sensory and digestive signals that bring the meal to an end) and satiety (state of fullness which follows a meal). These effects depend on the general subject characteristics including age, sex, ethnicity, social stratification, and education, as well as physical features such as body weight, BMI, body composition, degree of dietary restraint, and circadian rhythms.

3.1.1. Ethnic, educational, and social determinants. The distribution of macronutrient intake differs among countries and cultures. Extreme variations in human food selection can occur in different geographical regions. Nevertheless, there is a fairly wide range of carbohydrate: protein: fat ratios within which energy balance can be maintained. Carbohydrate intake can range from 3 to $82 \%$ of total energy, fat intake from 6 to $54 \%$, while protein intake is typically at least $11 \%$. Within a culture or country, dietary changes take place with changes in food supply. Numerous studies have concluded that along with physical characteristics, the subjects' ethnic, educational, and social background has an important influence over the macronutrient composition of their daily intake.

3.1.2. Circadian rhythms. Under normal circumstances, energy and macronutrient intakes follow a circadian pattern, with breakfast being relatively high in carbohydrate and dinner being relatively high in fat. This appears to hold true for lean as well as obese subjects (Kant et al. 1995).
Variation in macronutrient intake within meals is mediated by macronutrient- and sensory-specific satiety (Rolls et al. 1988; Stubbs, 1995), resulting in a more-or-less stable macronutrient intake over a usual day.

\subsection{Effects of macronutrient intake on energy intake, hunger, satiety and metabolism}

3.2.1. Fat intake in relation to energy balance. Dietary fat is the main determinant of the energy density of the diet after water. Because it can be stored with minimal additional weight, fat is the primary energy depot in the body. The fat content of the diet has an effect on body fat as a function of the effect of dietary fat on energy intake (Westerterp et al. 1996). Adaptation of food intake to the energy density of food is observed as adaptation of portion size in relation to energy density, and as adaptation of quantitative food choice from different energy density categories.

When people change to a diet with a lower or a higher energy density, a change in energy intake has been observed. Duncan et al. (1983) reported that energy intake can be nearly twofold higher $(12.5 \mathrm{MJ} / \mathrm{d})$ on a highenergy-density diet $(6.5 \mathrm{~kJ} / \mathrm{g})$ compared with energy intake $(6.5 \mathrm{MJ} / \mathrm{d})$ on a low-energy-density $\operatorname{diet}(3.0 \mathrm{~kJ} / \mathrm{g})$ in subjects eating to satiety. Following subjects provided with different diets in which carbohydrate was exchanged for fat, Lissner et al. (1987) reported energy intakes of $8.7 \mathrm{MJ} / \mathrm{d}$ on a low-fat (15-20\% energy) diet, $9.8 \mathrm{MJ} / \mathrm{d}$ on a medium(30-35\% energy) fat diet, and $11.4 \mathrm{MJ} / \mathrm{d}$ on a high(45-50\% energy) fat diet. In both cases, there was little compensation with respect to energy intake vis-à-vis the type of diet during the $14 \mathrm{~d}$ observation period. The subjects tended to be in energy balance on the medium-fat diet, lost weight on the low-fat diet and gained weight on the high-fat diet. Kendall et al. (1991) provided subjects with a low(20-25\% energy) fat and a control (30-35\% energy as fat) diet over a period of 11 weeks and, again, energy intakes were lower $(7.6 v .8 .6 \mathrm{MJ} / \mathrm{d})$ and weight loss greater $(2.5 v$. $1.3 \mathrm{~kg}$ ) on the low-fat diet. However, there was a significant increase in energy intake over the 11-week period consequent to the low-fat diet, while intake did not change significantly in relation to the control diet. The preceding studies suggest that the fat content of the diet has an effect on body fat as a function of the effect of dietary fat on energy intake.

3.2.2. Fat and carbohydrate intake in relation to satiety. A number of studies have shown that dietary fat has a relatively weak effect on satiety, and that this tends to favour overfeeding (Blundell \& Burley, 1992). Comparing the satiating effects of fat and carbohydrate, Rolls \& Hammer (1995) concluded that there is a small, but significant, insensitivity to energy from fat. Perhaps not only insensitivity to energy from fat, but also masked sensory perception of fats in some solid foods, may explain why fat promotes overfeeding. Many sweet, high-fat foods in which the fat is masked by sugars are commonly identified as carbohydrate-rich (Drewnowski \& Schwartz, 1990). The sweet desserts that seem to be especially favoured by obese women (Drewnowski et al. 1992) may not even be recognized as high-fat foods. 
3.2.3. Relative levels of fat, carbohydrate and protein intake in relation to satiety and metabolism. Macronutrient selection and compensation and diet-induced changes in nutrient balance theoretically occur to the extent that fat, protein and carbohydrate have independent effects on appetite regulation or differing satiating efficiencies. In studies of up to 2 weeks duration under free-living conditions (de Castro, 1987), as well as in laboratory studies (Blundell \& Burley, 1992), protein has been shown to be the most effective at suppressing energy intake, followed by carbohydrate, with fat having the weakest effect on satiety.

Short-term changes in nutrient metabolism result from changes in the macronutrient composition of the diet (Verboeket van de Venne \& Westerterp, 1991) and can affect post-ingestive satiety as well. One physiological adaptation that appears is the approach of $R Q$ values towards food quotient values (Shetty et al. 1994), that is, where the profile of metabolic fuels utilized by the body changes with the composition of the diet.

The hierarchy in the immediacy with which recently ingested macronutrients are metabolized is protein - carbohydrate - fat (Stubbs, 1995). The same hierarchy appears in satiating efficiencies of the macronutrients, and this is believed to have a metabolic component. This view is supported by results from diet-induced thermogenesis measurements in normal-weight men and women made during and after the consumption of a lunch offered on three different occasions in a full-fat version, an identical but reduced-energy-reduced-fat version, and in an isoenergetic (to the full-fat lunch type)-reduced-fat version. Subsequent $\mathrm{RQ}$ values corresponded to the food quotients such that the RQ was significantly lower after the full-fat lunch (low food quotient) than after the two reduced-fat lunches (higher food quotient) (Westerterp-Plantenga et al. 1997b). Moreover, satiety scores were positively related to the magnitude of diet-induced thermogenesis expressed as an absolute increase in metabolic rate during and after the meal.

It remains difficult to distinguish between macronutrient- and sensory-dependent food selection, as well as to distinguish between macronutrient-specific satiety and sensory-specific satiety, but macronutrient-specific satiety probably has a sensory-specific component. The mechanism that produces sensory-specific satiety is dependent primarily on activity in the processing systems for olfactory and taste information in the brain, whereas macronutrient-specific satiety is more probably an interaction with gastrointestinal feedback or energy monitoring signals (Rolls \& Rolls, 1997).

3.2.4. Alcohol intake and satiety. Not much is known about the effects of alcohol on hunger, satiety, and food intake in relation to body weight. Community survey studies tend to support the anecdotal evidence showing that in moderate alcohol consumers, total energy intake increases when alcohol is introduced into the diet (e.g. Rissanen et al. 1987). This suggests that energy derived from alcohol is not recognized or is not regulated by the body. Appetite remains unchanged or even heightened and, therefore, there is no compensatory decrease in food intake. However, the epidemiological evidence suggests that women who consume moderate amounts of alcohol tend to have a lower
BMI than abstainers (Colditz et al. 1991). Studies conducted in a metabolic ward suggest that an addition of a large amount of alcohol per day results in no additional weight gain (Priola \& Lieber, 1972). Despite speculation that alcohol might be metabolized less efficiently than other substrates, with a large amount of energy being lost as heat during so-called futile cycles, numerous metabolic studies have failed to show greater heat production following alcohol $v$. carbohydrate or fat ingestion (e.g. Sonko et al. 1994).

Foltin et al. (1993) measured the effect of ethanol on subsequent food intake within a metabolic ward, concluding that alcohol-derived energy appears to be under normal physiological regulation, decreasing food intake in a manner similar to that of isoenergetic carbohydrate sources. This suggests that alcohol is as satiating as carbohydrate. Other dietary studies have shown that when alcohol is included in the diet, there is little or no reduction in food intake, unless physiological control is in part over-ridden by social and environmental factors (de Castro \& de Castro, 1989). More recently, Rumpler et al. (1996) investigated the effects of an isoenergetic substitution of ethanol for dietary carbohydrate on energy expenditure and body composition, and showed that, on an energy basis, ethanol and carbohydrate are utilized with the same efficiency. However, Tremblay \& Saint-Pierre (1996) reported that when alcohol is consumed during a meal, its energy content is not compensated for by an equivalent decrease in energy intake from other macronutrients and thus, total energy intake increases when alcohol is consumed. Thus, a discrepancy remains between the epidemiological data which tend to indicate an inverse relationship between alcohol consumption and body weight, and well-controlled metabolic studies, which do not show this effect.

\subsection{Functional properties of macronutrient substitutes}

Nowadays, various commercially-produced foods claim to influence appetite and satiety in 'new and beneficial' ways. To this end, the functional aim of macronutrient substitutes (e.g. high-intensity sweeteners and fat-replacers) is to help consumers improve their diet by giving them an opportunity to reduce sugar $(17 \mathrm{~kJ} / \mathrm{g})$ and/or fat $(38 \mathrm{~kJ} / \mathrm{g})$ intake, with the short-term objective of controlling energy intake, and the long-term objective of weight loss or weight stability (Bellisle \& Perez, 1994). The studies that have been carried out to test their efficacy have varied widely in design and scientific merit.

3.3.1. The preload paradigm. In studying the influence of reduced-energy substitutes on food intake and energy regulation, a first course 'preload' (i.e. a food or drink manipulated according to energy and/or macronutrient content) is typically ingested by volunteers, with subsequent food intake serving as the dependent variable. One or several hours following ingestion, the subject's spontaneous intake is measured under laboratory conditions, and the differential carry-over satiety effects of preload ingestion on subsequent eating behaviour are determined (de Graaf $e t$ al. 1992). Ratings of subjectively perceived hunger or satiety, desire to eat, or prospective intake are obtained following the intake of the preload (Blundell \& Green, 1996). 
3.3.2. The issue of compensation. Behavioural responses to energy-reduced substitutes for regular foods can differ as a result of learning based on repeated exposure (Booth et al. 1976). Learned adaptation may take anything from a few days (Louis-Sylvestre et al. 1987) to several months (Prewitt et al. 1991). Various levels of compensation have been reported over the course of a few hours following the ingestion of low-energy, low-sugar, or low-fat loads (Booth, 1991; de Graaf et al. 1992). Stimulation of eating has also been observed after the oral intake of sweettasting foods and drinks containing intense sweeteners (Blundell \& Hill, 1986), although this effect remains controversial (Rolls, 1991).

Compensation remains the most critical issue vis- $\grave{a}$-vis the response to macronutrient substitutes. In studies on possible energy intake compensation after low-fat diets, complete macronutrient intake compensation has not been shown (e.g. Blundell et al. 1991, 1993). In everyday life, it is nearly impossible to compensate specifically for nutrients since most foods are of composite nutritional content (Beaton et al. 1992). Compensation appears more likely to be observed in male ( $v$. female) subjects, and more apparent when the energy difference between the regular and the energy-reduced stimulus is large. Energy compensation also depends on dietary restraint, duration of the use of the replacer, and on whether the fat is replaced in snacks or in meals. A 6-month follow-up of adults consuming prescribed diets showed that a change in the body fat mass was observed only when total energy intake was also changed (Westerterp et al. 1996).

It has been suggested that replacement of sugars by intense sweeteners might theoretically lead to a net increase in the proportion of fat in the diet (Beaton et al. 1992). Such an effect would make intense sweeteners counter-functional and deserves to be investigated under carefully-controlled conditions. Thus, it is possible, but not assured, that intense sweeteners, as a functional ingredient in palatable foods with reduced energy, could aid in energy control and weight-reduction (Rolls, 1991).

3.3.3. Highlight: sucrose polyester. A particularly interesting class of non-absorbable fat replacers are the so-called sucrose polyesters (SPE). The main questions that have been addressed involve the effects on energy intake and food choice in various groups of subjects who differ with respect to eating behaviour. When SPE replaced conventional fats in the diet of homogeneous groups of lean men, for example, energy, but not macronutrient, compensation was observed (Rolls et al. 1992). When the behaviour of subject groups characterized by their level of 'dietary restraint' (limitation of food intake in terms of meal size, meal frequency, and food choice) was contrasted with appropriate controls, normal-weight, 'unrestrained' men compensated accurately for given energy preloads, regardless of the nutrient composition, whereas normal-weight, 'restrained' men did not exhibit such orderly energy intake compensation. However, neither normal weight nor obese females, regardless of whether they could be characterized as restrained or unrestrained eaters showed orderly compensation for energy preloads (Rolls et al. 1994).

No difference in energy intake compensation between restrained and unrestrained eaters has been found with low-fat lunch meals (Chapelot et al. 1993) nor with energy-reduced lunches (Westerterp-Plantenga et al. 1994). Hulshof et al. (1995) found no energy intake compensation in women in the short term, but in men they found a tendency to compensate. When the fat was replaced by SPE, energy intake compensation was less than $50 \%$, but when the fat was replaced by water, it was $66 \%$. Employing a medium-term (12 d) protocol, de Graaf et al. (1996) reported that less energy was consumed per day when fat was replaced by SPE; i.e. the percentage of energy from fat decreased from $43 \%$ to $32 \%$ and this was accompanied by a corresponding decrease in body weight.

Westerterp-Plantenga et al. (1997a) reported that in dietary unrestrained and post-obese, restrained subjects, a significant reduction in energy intake and changes in macronutrient compositions were achieved by replacement of fat by SPE in snacks. In normal weight, restrained women, significant energy intake reductions and changes in macronutrient compositions were also achieved by similar meal manipulations. In neither case were deviations in hunger and satiety noted.

Cognitive influences have also been investigated with regard to the energy or macronutrient content of test meals. Some workers have shown that subjects can be misled by information regarding fat content (Caputo \& Mattes, 1993), while in other cases, no effect of true or false information has been observed (Chapelot et al. 1993).

\subsection{Modulating food intake through palatability enhancers: the case of monosodium glutamate}

Palatability is not only a vital issue when considering how to limit food intake, it is also critical when attempting to augment intake in populations at risk of nutritional deficiency. Foods are heated, salted, spiced, and decorated, all with the objective of enhancing palatability. However, one of the advantages of a non-traditional 'palatability enhancer', such as monosodium glutamate (MSG), is its capacity to augment food intake without noticeably changing the sensory aspects of the food (Yamaguchi, 1991). Activation of discrete sensory receptors on the tongue for the 'umami' taste is believed to be responsible for the stimulating effects of MSG (Yamaguchi, 1987).

Several short-term studies have shown a clear increase in intake when food palatability is enhanced. However, as very few studies have investigated the effects of manipulating test foods over the course of many days or weeks, the longterm potential of MSG remains unclear. There is some indication that while responsive persons are likely to eat more when exposed to a sudden improvement of diet, after a few days of exposure, intake generally stabilizes at a level that does not lead to body-weight gain (Rodin \& Slochower, 1976). Adding MSG to several foods typically encountered in a Western diet has a positive action on ratings of palatability obtained in classic sensory evaluation tests. Adding MSG can lead to increased intake of many foods on first exposure (Beauchamp et al. 1987) and, when added on repeated occasions, apparently contributes to the acquisition of a liking for the MSG-containing foods (Bellisle $e t$ al. 1991). Sweet-tasting substances (Perez et al. 1994; Reid \& Hammersley, 1995) and MSG are the only palatability 
agents which have been shown to influence food intake beyond the immediate ingestion of the palatable food itself. The current challenge is to ascertain how manipulating the palatability of various foods over the long term affects intake. MSG is an efficient way to influence within-meal food selection (Bellisle et al. 1996).

\section{Foods and cognitive performance}

\subsection{Overview}

In general, the literature on the effects of foods and food constituents does not cover a wide range of food types or food components. In addition, the measures of cognitive performance used are usually limited to a small number of well-known tasks or tests. There is considerable scope for more and better research using clearly defined nutritional manipulations or nutrients and an extended range of sensitive and relevant cognitive tasks.

Nutritional manipulations shown to influence cognitions include missing meals, dieting and snacking. Macronutrients such as carbohydrate and fat have been shown to both impair and improve certain aspects of cognitive performance, as have other food components (e.g. vitamins, glucose and tryptophan). Well-documented effects on cognitive performance have been observed following administration of caffeine and alcohol, although the effects tend not to be as great as those which follow psychotropic pharmaceutical preparations (Hindmarch et al. 1991).

\subsection{Performance tasks}

In principle, a large number of mental or cognitive tasks are potentially able to demonstrate the effects of foods on performance. In practice, however, a limited number of tests have been used. Some of the more frequently used are listed in Table 1.

In general, performance tasks can examine a number of skills or abilities concerning the following functions: perception, memory, attention and arousal, information processing, accuracy and speed of movement. In addition to the tasks listed in Table 1, other tests which have not been used frequently include digit symbol substitution (information processing, speed and accuracy of encoding), critical flicker fusion threshold (measure of central nervous system arousal), Stroop test (measure of speed of resolution of perceptual conflict), Corsi block tapping (spatial memory), and various types of reasoning (logical, mathematical, abstract). There are also specialized and sensitive tests used in educational work, psycho-geriatrics or in the assessment of neurological impairment. These have not been used with foods but have the potential to detect changes in important functions in response to dietary manipulations.

The tasks set out here usually represent single components which form part of more complex skills and abilities; for example, car-driving ability or operating machinery. In choosing a task, much depends on whether an immediate (short-term) effect of food is expected or whether a chronic (long-term) adaptation to a diet is being examined. Cognitive performance encompasses not only measures of speed (reaction time) but also of processing accuracy (measures of accurate and inaccurate detection), and interventions may elicit changes in function in some or all of these performance components. Recent advances in computer technology have meant that these tasks can be administered in a structured, carefully-controlled fashion, with extremely accurate measurement of reaction time and the rate of correct and erroneous responses.

\subsection{Effects of nutritional manipulations on performance}

4.3.1. Food v. no food first thing in the morning. It is necessary at the outset to demonstrate that food itself (compared with no food) will influence cognitive performance. A number of studies (see Table 2), beginning with the Iowa breakfast studies (Tuttle et al. 1954), have demonstrated that missing breakfast can have detrimental effects on performance in terms of reaction time tasks, spatial memory and immediate word recall (Benton \& Sargent, 1992; Smith et al. 1994a). While some aspects of memory

Table 1. Functions assessed by cognitive tests

\begin{tabular}{|c|c|c|}
\hline Function & Test & Description \\
\hline $\begin{array}{l}\text { Vigilance (also known as attention), rapid } \\
\text { information processing or continuous } \\
\text { performance }\end{array}$ & Bakan test & $\begin{array}{l}\text { A series of numbers are presented visually in rapid succession on } \\
\text { a VDU screen. The subject }(S) \text { has to respond by depressing a } \\
\text { key when a sequence of three odd or three even digits is } \\
\text { detected. }\end{array}$ \\
\hline Reaction time (decision time and movement time) & $\begin{array}{l}\text { Simple (SRT) or } \\
\text { choice (CRT) }\end{array}$ & $\begin{array}{l}\text { Stimulus appears (visual or auditory) and S must make a single } \\
\text { response usually by depressing a key. In CRT one of a number } \\
\text { of stimuli may appear and S must make one of two responses } \\
\text { (e.g. left hand, right hand) according to the type of stimulus. }\end{array}$ \\
\hline Working memory (short-term memory) & $\begin{array}{l}\text { Immediate } \\
\text { recall } \\
\text { Word } \\
\text { recognition }\end{array}$ & $\begin{array}{l}S \text { shown a list of twenty words at a given rate (e.g. } 1 \text { per } s \text { ). At end } \\
\text { of presentation } S \text { recalls the words. } \\
S \text { must recognize rather than recall. }\end{array}$ \\
\hline Immediate memory & Digit span & $\begin{array}{l}S \text { must remember (recall) series of items in forward or reverse } \\
\text { order. }\end{array}$ \\
\hline Psycho-motor performance (tracking ability) & $\begin{array}{l}\text { Pursuit rotor } \\
\text { Tapping task }\end{array}$ & $\begin{array}{l}S \text { must trace a shape (maze) with a stylus under time pressure. } \\
\text { Error score computed. } \\
S \text { must tap in rapid succession to a key. }\end{array}$ \\
\hline
\end{tabular}

VDU, visual display unit. 
seem to be susceptible to the effects of missing breakfast, other aspects of performance are not affected (Smith et al. 1994a). These studies were all performed on adult subjects but differed in terms of the experimental design and the particular performance measures employed. Studies in children and adolescents show clearer deficits on a wide range of performance tasks following omission of breakfast, with greater effects in under- and malnourished children (Vaisman et al. 1996).

A number of studies have shown that breakfast $v$. no breakfast (early morning meal) or high- $v$. low-energy breakfasts cause changes in sustained attention, reaction time and memory. Energy improves performance in all of these and may be related to blood glucose levels, with high-carbohydrate meals producing the best effects.

4.3.2. Effects at midday. When nutritional manipulations are made at midday, performance on attention and reaction time tasks is usually impaired (see Table 3 ). One study has shown that eating lunch ( $v$. no lunch) worsens performance on attention and reaction time tasks (Smith \& Miles, 1986b). A large lunch-time meal contributes to the 'post-lunch dip' in performance. This means that performance on sustained attention tasks is impaired in the early afternoon compared with late morning, an effect that is effectively abolished by administering caffeine.

The obvious differences in post-breakfast and post-lunch psychological effects open the question of the reasons why the same behaviour, that is eating, is followed by contrasting or even opposing consequences. Time of day (circadian biological effect), size of meal or macronutrient selection could all contribute to the observed differences. The postlunch dip, a clearly undesired effect in Western industrial societies, could be a fruitful area of research for the development of functional foods.

4.3.3. Effects following evening meals. A few studies have examined the effects of meals eaten late in the day. Effects are mixed, with logical memory being improved by a meal, but no changes occurring in sustained attention, word recall or word recognition (Smith et al. 1994b). Visual search under high memory load is impaired by both early and late evening meals (Smith \& Miles, 1987). It should be kept in mind that optimal performance is usually seen with the type of meal habitually consumed by the subjects, and any change from the usual nutrient composition normally leads to deterioration. Differences in performance could therefore be ascribed to psychological or physiological phenomena. Moreover, discrepancies are often seen between subjective (rating scales, questionnaires) and objective (cognitive tasks) measures of performance.

\subsection{Influence of macronutrient ratios and individual nutrients}

A good deal of work has been prompted by the idea that foods varying in the proportions of carbohydrate and protein would influence performance via changes in brain

Table 2. Effect of breakfast (BF) on performance

\begin{tabular}{|c|c|c|c|}
\hline Reference & Type & Tasks & Effect \\
\hline \multicolumn{4}{|l|}{ Adults } \\
\hline Tuttle $(1950,1952)$ & No BF $v$. BF & 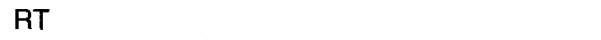 & poorer \\
\hline Benton \& Sargent (1992) & No BF $v$. BF & $\begin{array}{l}\text { memory: spatial } \\
\text { immediate work recall }\end{array}$ & $\begin{array}{l}\text { poorer } \\
\text { poorer }\end{array}$ \\
\hline Dickie \& Bender (1982) & BF v. no BF & $\begin{array}{l}\text { arithmetic } \\
\text { STM }\end{array}$ & $\begin{array}{l}\text { no effect } \\
\text { no effect }\end{array}$ \\
\hline Smith et al. (1994a) & (a) BF & $\begin{array}{l}\text { sustained attention } \\
\text { pulse rate }\end{array}$ & $\begin{array}{l}\text { no effect } \\
\text { increased }\end{array}$ \\
\hline & (b) $\mathrm{BF}$ & $\begin{array}{l}\text { free recall } \\
\text { recognition memory } \\
\text { semantic memory } \\
\text { logical reasoning }\end{array}$ & $\begin{array}{l}\text { improved } \\
\text { improved } \\
\text { no effect } \\
\text { impaired }\end{array}$ \\
\hline Michaud ef al. (1991) & $\begin{array}{l}\text { Normal } v \text { HE intake } \\
\text { at BF }\end{array}$ & $\begin{array}{l}\text { STM, immediate recall } \\
\text { concentration }\end{array}$ & $\begin{array}{l}\text { improved (HE) } \\
\text { impaired (HE) }\end{array}$ \\
\hline Lloyd et al. (1994) & $\begin{array}{l}\text { Low fat /high CHO BF } \\
\text { v. med/high fat }\end{array}$ & test battery & improved with high-CHO BF \\
\hline \multicolumn{4}{|l|}{ Children } \\
\hline Pollitt et al. $(1981,1983)$ & No BF & $\begin{array}{l}\text { problem-solving (MFF) } \\
\text { immediate memory (recall of last item-recency) }\end{array}$ & $\begin{array}{l}\text { poorer } \\
\text { improvement }\end{array}$ \\
\hline $\begin{array}{l}\text { Simeon \& Grantham-McGregor } \\
\text { (1989) }\end{array}$ & BF $v$. no BF & $\begin{array}{l}\text { verbal fluency and coding } \\
\text { numeric digit span backwards } \\
\text { MFF test }\end{array}$ & $\begin{array}{l}\text { poorer } \\
\text { poorer } \\
\text { poorer }\end{array}$ \\
\hline Chandler et al. (1995) & BF v. no BF & $\begin{array}{l}\text { four tests of cognitive function } \\
\text { verbal frequency }\end{array}$ & $\begin{array}{l}\text { no effect } \\
\text { poorer }\end{array}$ \\
\hline Cueto (1995) & BF v. no BF & $\begin{array}{l}\text { STM speed } \\
\text { geometric pattern discrimination }\end{array}$ & $\begin{array}{l}\text { poorer } \\
\text { poorer }\end{array}$ \\
\hline Wyon et al. (1997) & HE $v$. LE BF & $\begin{array}{l}\text { creativity } \\
\text { physical endurance } \\
\text { addition } \\
\text { multiplication }\end{array}$ & $\begin{array}{l}\text { improved (HE) } \\
\text { improved } \\
\text { more errors (LE) } \\
\text { no effect }\end{array}$ \\
\hline Connors \& Blouin (1983) & No BF v. BF & $\begin{array}{l}\mathrm{RT} \\
\text { arithmetic test }\end{array}$ & $\begin{array}{l}\text { more errors } \\
\text { improved }\end{array}$ \\
\hline
\end{tabular}

CHO, carbohydrate; HE, high energy; LE, low energy; MFF, matching familiar figures; RT, reaction time; STM, short-term memory. 
Table 3. Effect of lunch on performance

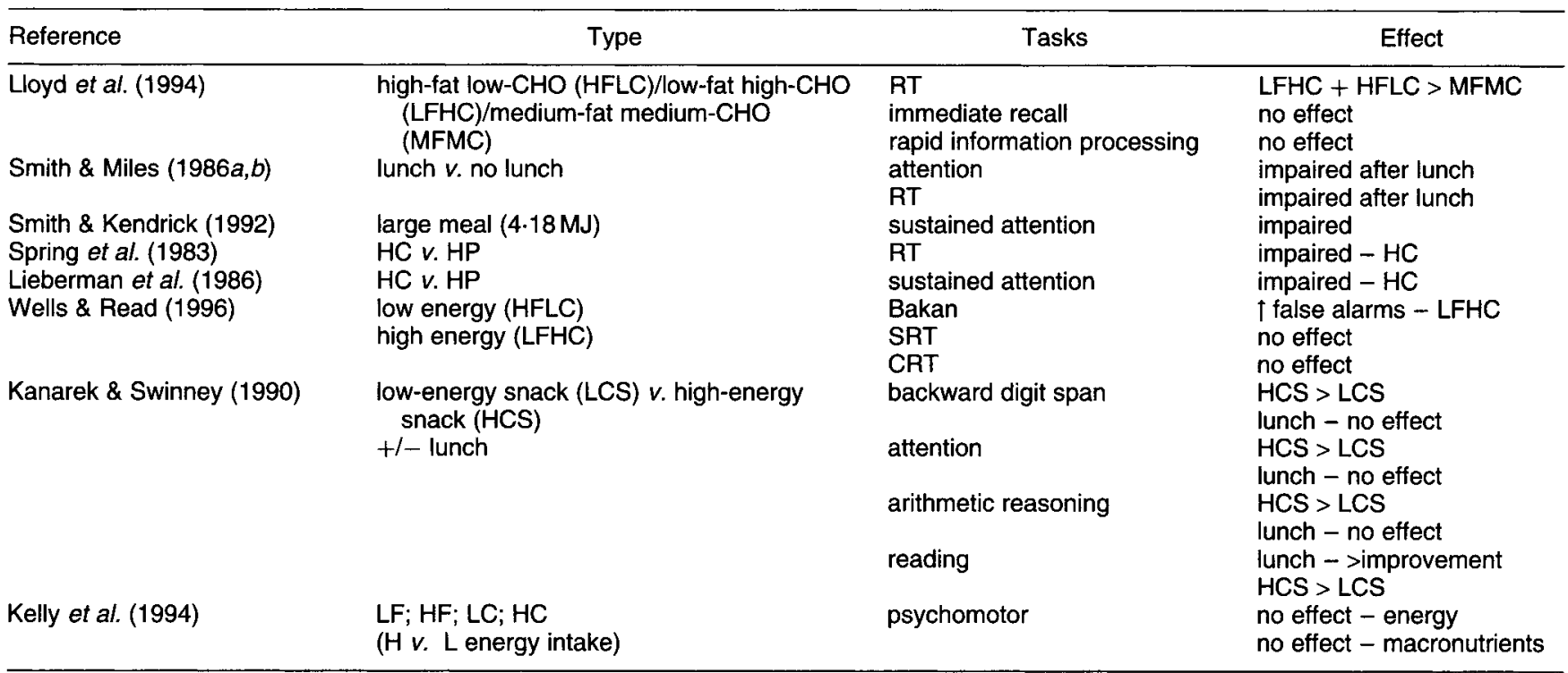

$\mathrm{CHO}$, carbohydrate; CRT, choice reaction time; HC, high carbohydrate; HP, high protein; RT, reaction time; SRT, simple reaction time.

serotoninergic function (Young, 1991). A number of psychological changes have been predicted from diets varying in carbohydrate and protein content but the evidence is, in fact, quite weak. However, several studies have found that highcarbohydrate meals do tend to produce greater drowsiness, sleepiness and calmness (e.g. Spring et al. 1987).

4.4.1. The carbohydrate-tryptophan connection. The theoretical background linking carbohydrate and serotonin (5-hydroxytryptamine) implies that the dietary effects are mediated by changes in the plasma ratio tryptophan : large neutral amino acids. The argument depends on the extent to which meals vary in carbohydrate and protein content. Circulating tryptophan exists in a free form and bound to blood albumin. After a high-carbohydrate meal (which must contain almost no protein), the insulin that is released causes branched-chain amino acids to be taken up into tissues, particularly muscle. Insulin also reduces the release of nonesterified fatty acids into the plasma; plasma non-esterified fatty acid concentration falls and albumin binding sites are liberated. Consequently, a high-carbohydrate meal elevates the tryptophan:large neutral amino acid ratio in the plasma. This, in turn, favours the uptake of tryptophan into the brain as the amino acids compete for the selective carrier across the blood-brain barrier. Consequently, carbohydrate meals increase brain tryptophan. Since the enzyme tryptophan hydroxylase (EC 1.14 .16 .4$)$ is normally not saturated with its precursor, the availability of tryptophan becomes the rate-limiting step in the synthesis of the neurotransmitter serotonin. The logic of this argument is that high-carbohydrate meals enhance serotoninergic neurotransmission in the brain (Fernstrom \& Wurtman, 1972). However, adding as little as $40 \mathrm{~g}$ protein $/ \mathrm{kg}$ to the meal can abolish the 'tryptophan effect' (Teff et al. 1989).

Administering tryptophan should produce similar effects to eating carbohydrate. Lieberman et al. (1983) compared the effects of tryptophan and tyrosine on four performance tasks: simple auditory reaction time, two-choice reaction time, grooved pegboard, and the Thurstone tapping task. The tryptophan treatment differed from tyrosine only on auditory reaction time but neither amino acid produced a response that differed from its own placebo. However, tryptophan did increase subjective ratings of fatigue-inertia and decreased feelings of vigour-activity on rating scales. In other tests, a high-carbohydrate lunch (compared with protein) was found to impair performance on the digit symbol substitution test, with a high starch load linked with slower reaction time but having no effect on a dichotic listening task (Lieberman et al. 1986).

Further studies using high-energy, high-carbohydrate snacks have examined effects on four cognitive tasks: digit span, arithmetic reasoning, reading and attention (Kanarek \& Swinney, 1990). In comparison with a low-energy soft drink containing aspartame, a high-carbohydrate snack of yoghurt improved digit span performance (greater recall) and enhanced performance in the attention task (continuous performance) in the late afternoon. Subjects receiving the energy-containing yoghurt (compared with a soft drink) solved more arithmetic problems in a shorter time. The consumption of lunch before testing had no effect on this performance. Lloyd et al. (1996) failed to find differences in objective performance following breakfasts with a low-, medium-, or high-carbohydrate content, but did find that the high-carbohydrate breakfast improved mood by reducing fatigue and dysphoria.

A simple-sugar load improves performance, probably due to a rise in blood glucose. A large carbohydrate meal is likely to produce variable effects on performance, depending on the presence of some protein with the carbohydrate. Although a very-low-protein (less than $40 \mathrm{~g} / \mathrm{kg}$ ) meal will trigger changes in serotoninergic neurotransmission, a usual meal, with a higher protein content, will not elicit the rise in tryptophan.

4.4.2. Dietary fat. Little decisive research has been carried out regarding the effect of dietary fat on performance. 
Comparisons of low- and high-carbohydrate and low- and high-fat lunches revealed no effects on psychomotor tasks (Kelly et al. 1994) but with $n 6$, the power was obviously low. A subsequent study (Lloyd et al. 1994) showed that optimal performance was seen with a medium-fat-medium-carbohydrate lunch, whereas higher proportions of either fat or carbohydrate caused subjects to be more drowsy, uncertain and muddled, impairing cognitive efficiency.

A comparison of four fat-carbohydrate combinations in human trials showed that all diets increased subjective lassitude (Wells \& Read, 1996). It was alleged that morning fat caused a greater depression of alertness and mood, but the study design was questionable and effects were weak. Smith et al. (1994b) showed that a high-fat meal did not affect logical reasoning or vigilance but did produce slower but more accurate performance on selective attention tasks. Little is known about the influence of the level of dietary fat saturation on human subjects, but work by Greenwood \& Winocur (1990) has shown that a diet high in saturated fat impairs learning acquisition in rats.

Studies have examined the effect of the fatty acid docosahexaenoic acid (DHA) on visual acuity in term and preterm infants (Carlson et al. 1996). There is evidence that DHA is important for normal visual development. Formula feeding provides linoleic acid but not DHA, which is available from human milk. Comparisons of the visual acuity of infants fed with either DHA or linoleic acid for at least 3 months showed a positive relationship between DHA status and visual acuity in infants fed with the DHA-enriched formula (Carlson et al. 1996).

4.4.3. Glucose. A substantial number of studies have shown generally beneficial effects of glucose on performance (see Table 4). A series of studies in elderly subjects showed enhanced effects on working (short-term) memory, and similar effects have been demonstrated in young adults (Benton \& Sargent, 1992). Following a glucose drink, blood glucose level correlated with improved decision time in a reaction time task (Benton \& Owens, 1993). Rising levels of blood glucose were associated with better recall than falling levels. The glucose-induced improvement was observed across a range of baseline blood glucose levels and, hence, was not the product of hypoglycaemia. Hypoglycaemia was associated with slower reaction times. The higher levels of blood glucose (following a glucose drink) correlated with faster information processing, better word recall, and improvement on the Stroop test.

4.4.4. Dietary choline. As noted earlier, precursors of neurotransmitters in the diet (and then in the plasma) can lead to increases in levels of the neurotransmitter in the brain. Choline is the precursor for acetylcholine. In animal studies, significant improvements in cognitive performance have been seen with choline-enriched diets. In young adults, one study showed an improvement in memory with choline. In elderly people (for whom memory disturbance is often a problem), however, the results have been disappointing. In a review of seventeen studies using choline or lecithin (a major source of choline in the diet), only one study found an improvement of memory in the majority of subjects (Bartus et al. 1982).

4.4.5. Vitamins and minerals. In the elderly, cognitive function and measures of intelligence are enhanced by supplementing the diet with pyridoxine, cobalamin, and folic acid (Goodwin et al. 1983). Further research is needed to determine to what extent these substances might arrest the decline in cognitive ability in old age. In children, multivitamin supplements have been claimed to produce superior performance on a test battery (Wechsler intelligence scale, non-verbal subscales) (Benton, 1992). However, this is controversial, and two studies have found negative effects (Crombie et al. 1990; Nelson et al. 1990). Few studies have considered specific vitamins, although Southon (reported in Nelson, 1992) found a positive correlation between plasma ascorbic acid, glutathione peroxidase (EC 1.11.1.9) activity, and non-verbal intelligence scores.

One factor that may be important in the interpretation of the results of these studies is the habitual diet of the children concerned. Nelson (1992) has suggested that where the diet is deficient in several nutrients, children may show poorer

Table 4. Effect of glucose on performance

\begin{tabular}{|c|c|c|c|}
\hline Reference & Experimental situation & Tasks & Effect \\
\hline $\begin{array}{l}\text { Pollitt et al. (1983) } \\
\text { Owens \& Benton (1994) } \\
\text { Gonder-Frederick et al. (1987) } \\
\text { Hall et al. (1989) } \\
\text { Manning et al. (1990) } \\
\text { Lapp (1981) } \\
\text { Hall et al. (1989) } \\
\text { Benton \& Owens (1993) } \\
\text { Holmes et al. (1986) } \\
\text { Herold et al. (1985) } \\
\text { Fourest-Fontecave et al. (1987) } \\
\text { Langan et al. (1991) } \\
\text { Deary et al. (1993) } \\
\text { Benton et al. (1994) }\end{array}$ & $\begin{array}{l}\text { children - food deprivation } \\
\text { glucose drink } \\
\text { blood glucose level } \\
\text { elderly } \\
\text { elderly } \\
\text { elderly } \\
\text { young adults } \\
\text { young adults } \\
\text { young adults } \\
\text { mild hypoglycaemia } \\
\text { mild hypoglycaemia } \\
\text { mild hypoglycaemia } \\
\text { severe hypoglycaemia } \\
\text { severe hypoglycaemia } \\
\text { glucose drink }\end{array}$ & $\begin{array}{l}\text { inspection time } \\
\text { simple reaction time (decision time) } \\
\text { memory } \\
\text { memory } \\
\text { memory } \\
\text { memory } \\
\text { memory } \\
\text { memory } \\
\text { RT } \\
\text { RT } \\
\text { RT } \\
\text { RT } \\
\text { RT } \\
\text { rapid information processing (Bakan) } \\
\text { Stroop } \\
\text { word recall }\end{array}$ & $\begin{array}{l}\text { negatively correlated with } \\
\text { performance } \\
\text { no effect } \\
\text { faster with } \uparrow \text { blood glucose } \\
\text { enhanced } \\
\text { enhanced } \\
\text { enhanced } \\
\text { enhanced } \\
\text { enhanced } \\
\text { enhanced } \\
\text { slower } \\
\text { slower } \\
\text { slower } \\
\text { slower } \\
\text { slower } \\
\text { faster with } \uparrow \text { blood glucose } \\
\text { enhanced with } \uparrow \text { blood glucose } \\
\text { (at start of task) } \\
\uparrow \text { recall with glucose drink }\end{array}$ \\
\hline
\end{tabular}

RT, reaction time. 
performance on tests of non-verbal intelligence quotient. Differences between studies in developed and developing countries suggest that the extent of the dietary deficiency is important and that supplementation programmes are more likely to produce improved performance in the latter than in the former environment.

4.4.6. Alcohol. Like caffeine, alcohol produces clear effects on cognitive function and can be used as a standard for the comparisons of nutritional or food manipulations. In general, alcohol impairs performance on psychomotor tracking, driving tasks, perception, and sustained attention (Hindmarch et al. 1991).

\subsection{The case of caffeine}

As might be expected, most studies have shown that caffeine use leads to an improvement in most measures of cognitive performance, particularly reaction time, vigilance, memory (speed of retrieval) and psychomotor performance (e.g. Smith et al. 1992). It has been suggested that caffeine possesses cholinergic cognition-enhancing properties (in contrast to acetylcholine precursors, cholinergic drugs have marked effects on memory). Caffeine can also improve selective attention, and faster reaction times are probably due to faster central and/or peripheral motor responses. There has been some debate as to whether effects depend on the level of caffeine consumption. Jarvis (1993) demonstrated increased word recall in high-caffeine consumers whereas Mitchell \& Redman (1992) found that high consumers performed consistently worse than low and moderate users. Rogers et al. (1995) found that the performance in a reaction time task was influenced by caffeine only in high, but not in low, users. Other subgroups of subjects who respond differently to caffeine are high (v. low) 'impulsives'. (Impulsivity is a tendency towards spontaneous, sometimes uncontrolled reactions. Impulsive people (impulsives) are identified using questionnaires.) Anderson \& Revelle (1982) reported that high impulsives enhance their performance following caffeine, while performance of low impulsives is impaired. High impulsives tended to profit from caffeine only in the morning when their arousal was low. Smith et al. (1991) found similar results with regard to group differences, but in this study high impulsives were sensitive to caffeine in the morning as well as in the afternoon.

\section{Functional effects of foods on activation or sedation}

\subsection{Overview}

The literature regarding the functional effects of foods on activation and sedation generally focuses on behaviours such as sleep, activity and hyperactivity, as well as several aspects of mood, including feelings of tension, calmness, drowsiness and alertness. The following section considers separately the effects of different food components, especially caffeine and the amino acid tryptophan, the dietary carbohydrate: protein ratio and, with regard to hyperactivity, the effects of sugar and food additives.

\subsection{Methods for assessing activation or sedation}

Effects regarding activation and sedation, relaxation and tension are often not tested directly, but are subsumed under influences on mood. Since affective states cannot be directly measured, research on mood has to rely on reports by the subject regarding his or her present state. The methods most often used to assess temporal aspects and changes of moods are adjective check lists and visual analogue scales. Adjective check lists are more or less lengthy lists of adjectives which the subject uses to describe his or her present emotional state. Dimensions of moods are typically explored using 'factor analysis' techniques such as visual analogue scales, which basically consist of a line anchored at both ends with the description of an emotional state (e.g. 'extremely angry' - 'not at all angry'). The subject indicates, through a mark on this line, to what extent the description applies to his or her present state.

With regard to sleep, methods include measurement of sleep latency, i.e. the time taken to fall asleep, subjective ratings of sleepiness or related feelings, drowsiness, and related performance measures such as reaction time, vigilance, or tasks requiring sustained attention.

5.2.1. Tryptophan. Behavioural and psychological effects of tryptophan are well-documented and summarized in several reviews (Hill \& Blundell, 1988). Sleep and feelings of fatigue are affected by tryptophan intake. In both adults and children, tryptophan reduces sleep latency and promotes feelings of drowsiness and fatigue (Steinberg $\mathrm{et} \mathrm{al}$. 1992).

5.2.2. Tryptophan, tyrosine, and 'jet lag'. Kits containing pills of tyrosine and tryptophan are currently marketed to combat 'jet lag'. It is thought that these substances could help individuals by adjusting their circadian rhythms after crossing several time zones during airline travel. Because tyrosine is a precursor to the catecholamines, higher plasma levels of tyrosine could stimulate catecholamine release, consequently promoting alertness, while tryptophan promotes sleepiness, as detailed earlier. If tyrosine is taken in the morning and tryptophan is taken in the evening, this might help to synchronize circadian rhythms more rapidly after a major change in the day-night cycle. However, there is no sound experimental evidence to support this hypothesis (Waterhouse et al. 1997).

\subsection{Carbohydrate v. protein: effects on performance}

In accordance with the previously mentioned results on the effects of tryptophan, several studies have found greater drowsiness, sleepiness and calmness after carbohydrate-rich meals compared with protein-rich meals (see Spring et al. 1987). However, the differences were not consistent across all subject groups and many mood and performance measures were unaffected by experimental condition. Although lunch and breakfast reportedly have different effects on fatigue or drowsiness, the relative direction of carbohydrate v. protein effects appears to be similar (Spring et al. 1983; Rosenthal et al. 1989): at noon, both protein- and carbohydrate-rich meals induce some drowsiness, but the effect is greater after carbohydrate. In the morning, any breakfast reduces fatigue in regular breakfast eaters; however, a 
carbohydrate-rich breakfast tends to reduce fatigue less than a protein-rich breakfast.

\subsection{Caffeine-driven activation}

A large number of studies have looked at the psychoactive effects of caffeine on the central nervous system (for reviews, see James, 1991; Nehlig et al. 1992). In general, caffeine is regarded as a psychostimulant. It also leads to increased anxiety at higher doses in some susceptible individuals. In many regular consumers of caffeine, the cessation of caffeine consumption is followed by adverse changes, such as headache, drowsiness and fatigue (Silverman et al. 1992). Richardson et al. (1995) found two patterns of results after deprivation from caffeine. After overnight $(13 \mathrm{~h})$ deprivation, subjects showed significantly increased levels of tiredness and drowsiness, and more anger and dejection. The other pattern was less clear-cut. After caffeine deprivation for $13 \mathrm{~h}$ or $7 \mathrm{~d}$, subjects tended to report poorer mood and more headache. Several studies have found that the symptoms of increased tiredness, drowsiness, anger, and dejection were present in subjects after overnight or $24 \mathrm{~h}$ deprivation, but not after longer deprivation periods. Thus, the recent use of caffeine determines to a large extent the present effects of caffeine (Rogers, 1995). This makes it difficult to determine whether the experimental results on effects of caffeine, often reported after an overnight caffeine deprivation, are due to beneficial effects of caffeine or to the amelioration of the negative consequences of short-term caffeine deprivation.

\section{Influence of food and individual nutrients on affective state}

\subsection{Overview}

Certain foods or individual nutrients have been implicated in behavioural distress involving mood shifts. One argument is that affected individuals self-medicate, using food or drink to combat aversive mood states characterized by frustration, anxiety, or depression. Alternatively, some individuals may refrain from eating certain foods in order to avoid their putative behavioural toxicity, according to the view that certain dietary constituents are aetiological agents for various forms of dysfunctional behaviour and negative affect (Christensen et al. 1989). For example, simple sugars have been variously blamed for disturbances in mood, sleep, and cognitive performance (Kruesi \& Rapoport, 1986).

\subsection{Diet-related dysphoria}

One phenomenon that has received significant attention is the concomitant occurrence of dysphoria, a state of feeling unwell or unhappy, with a predilection for foods high in sugar or starch, so-called 'carbohydrate craving' (Wurtman, 1984; Lieberman et al. 1986). This is consistent with the observation that preferences for sweet and starchy foods increase during depressive episodes (Fernstrom et al. 1987) and with reports that carbohydrates can provide a temporary elevation in energy (Thayer, 1987) and mood (Lieberman et al. 1986). Certain clinical conditions, including premenstrual syndrome (Wurtman et al. 1989), bulimic episodes
(Rosenthal \& Hefferman, 1986), seasonal affective disorder (Rosenthal et al. 1989), and atypical depression (Wallin \& Rissanen, 1994), as well as withdrawal from alcohol, caffeine and tobacco over-consumption (Rosenthal et al. 1989), have similarly been linked to increases in carbohydrate intake. Patients describe themselves as anxious, tense, or depressed before a carbohydrate snack and peaceful and relaxed afterwards (Wurtman, 1984).

The paradox of this approach is that any improvement in mood accompanying carbohydrate snacks or meals, as with alcohol (Lloyd \& Rogers, 1995) and probably drug use, is typically followed by a more prolonged period of increased anxiety, fatigue, and depression (Thayer, 1987; Milgram, 1990). The motivation to alleviate the negative mood state is high and, as such, it appears to be the initial positive effect and not the ensuing negative consequence that is remembered (Tamerin \& Mendelson, 1969). This is consistent with recent work demonstrating that chocolate did not improve general mood state in a group of self-identified 'chocolate addicts'. The mood lift experienced was short-lived and the strategy self-defeating; eating chocolate ultimately led to feelings of guilt not detected in controls (Macdiarmid \& Hetherington, 1995). It is presently held that sensory, rather than pharmacological, effects underlie the satisfaction experienced when a craving for chocolate is met (Michener \& Rozin, 1994).

\subsection{Central neurochemical activity and mood state}

The proposed relationship between the composition of foods and their putative mood-altering effects has been linked to the serotonin hypothesis of Fernstrom and Wurtman (Fernstrom \& Wurtman, 1972; Fernstrom, 1994) (see section 4.4.1.). Central serotonergic imbalance has been linked to disorders of food intake and affective behaviour. As to whether these are interrelated via dietary tryptophan insufficiency and so-called carbohydrate craving, the experimental support is mixed. Young et al. (1985) reported that tryptophan depletion in human subjects can lead to mild dysphoria, but Benkelfat et al. (1994) recently suggested that this occurs only in susceptible individuals such as subjects with a multi-generational history of major affective disorders. Early workers demonstrated that carbohydrate can ameliorate dysphoria (Lieberman et al. 1986; Wurtman et al. 1989); however, Reid \& Hammersley (1995) recently failed to find any effect of carbohydrate ingestion on measured mood state immediately, 30 or $60 \mathrm{~min}$ after ingestion.

Studies have failed to find carbohydrate $v$. protein effects on mood, despite significant effects on the tryptophan: large neutral amino acid ratio (Deijen et al. 1989; Christensen \& Redig, 1993). One problem is that the influence of dietary manipulations on the plasma tryptophan : large neutral amino acid ratio is probably too small to produce significant changes in brain serotoninergic function (Young, 1991). However, there is some evidence to suggest that diet can influence the tryptophan: large neutral amino acid ratio (Schweiger et al. 1986; Goodwin et al. 1987). The latter study also found significant correlations between carbohydrate ratio, amino acid ratio and mood. 
Interest in 'carbohydrate cravers' as a clinical subpopulation may be waning. Schlundt et al. (1993) failed to find evidence that self-labelled cravers of sweet foods consume an abnormally high proportion of high-carbohydrate, lowprotein foods, and Drewnowski (1990), noting that socalled carbohydrate cravers typically identify chocolate, ice-cream, and other desserts as their preferred foods, each of these deriving the highest proportion of their energy from fat, has questioned whether, in fact, such a clinical subgroup exists.

\subsection{Other links between nutrition, mood and brain serotonin levels}

Tryptophan deficiency has recently been linked to dysphoriarelated alcohol abuse. Adams et al. (1995) have suggested that alcohol abuse may be a result of abnormal serotonergic activity in certain individuals, based on the hypothesis that alcohol can mimic the central effects of serotonin. Although purely speculative at this point, ethanol may merit further study with respect to its capacity to modulate central serotonin activity and ameliorate depressive episodes.

Certain vitamin deficiencies have also been implicated in psychiatric symptoms such as psychosis and depression. Pellagra, resulting from severe niacin deficiency, is the classic example (Lipton \& Kane, 1983). Folate deficiency is characterized by deficient levels of its metabolic precursor, $S$-adenosylmethionine. In view of the possibility that the anti-depressant effects of $S$-adenosylmethionine may raise brain serotonin levels, folate deficiency has been implicated in serotonin-related depressive episodes (Young, 1993). In the absence of deficiency, however, there is no evidence that vitamin supplementation improves mood or is a potential treatment for behavioural problems (Kruesi \& Rapoport, 1986).

Does carbohydrate intake improve mood state by normalizing central serotonergic activity or, as is the case with vitamin (or mineral) supplementation, is function (e.g. affective state) merely restored subsequent to a tryptophan imbalance or deficiency? The apparent co-morbidity of dysphoria and so-called carbohydrate craving requires further exploration in light of evidence that dietary tryptophan modulates affective behaviour. Special attention should be given to dose-response effects in wellcharacterized population subgroups and, in particular, to resolving the paradox between short- and long-term effects.

\section{Nutrition and endorphins}

A reciprocal relationship has been proposed to exist between the intake of various foods and the activation of endogenous opioid responses in the central nervous system. Matsumura et al. (1982) established that the oral ingestion of a light meal and the consequent stimulation of gastric function were associated with the increase in plasma $\beta$ endorphin levels in human subjects. This suggests that endorphins, endogenous opioid substances involved in pain perception and reward, could be increased in the post-meal period as a result of the normal processing of food in the digestive tract. Ingesting foods might therefore be a means of reducing pain perception and altering mood state.
At present, the literature remains confusing. Several experiments in isolated rat pups have shown that infusion of sugar into the mouth stops distress vocalizations, again suggesting a calming, rewarding effect of sucrose (Blass et al. 1987; Blass \& Fitzgerald, 1988), while Dum et al. (1983) reported that a palatable food reward (chocolate milk) appeared to influence $\beta$-endorphin activity in rats, as judged by their behavioural response to administration of the opioid receptor antagonist naloxone. Hyperphagic obese rats are more tolerant to painful stimuli than controls, which suggests a higher level of opioid activity, perhaps due to overeating (Ramzan et al. 1993).

In rats with continuous access to a palatable sucrose solution, hypersensitivity rather than hyposensitivity to painful stimuli has been observed (Roane \& Martin, 1990). Pain sensitivity in rats has also been shown to decrease after food deprivation (McGivern \& Berntson, 1980). Melchior et al. (1991) found no increase in circulating $\beta$-endorphin levels in human subjects after the intake of a highly palatable meal, while high levels of $\beta$-endorphins have been found in patients with anorexia nervosa (Kaye et al. 1982). Women who consume palatable foods show increased pain tolerance, as measured using a pressure algometer, compared with those receiving unpalatable foods, neutral foods, or nothing (Mercer \& Holder, 1997).

\section{Safety issues}

\subsection{Overview}

The safety of food additives and novel ingredients can only be assured after identifying limits of potential toxicity and, from these data, establishing acceptable daily intake levels. Populations with special dietary needs, e.g. the young, the elderly, and persons at risk of certain metabolic diseases, such as phenylketonuria, merit particular consideration. Whether the substance is used as a food additive or replacer, continued surveillance is necessary in order to identify potentially adverse or toxic effects, particularly with regard to cumulative intakes.

\subsection{Tryptophan}

An individual consuming about $100 \mathrm{~g}$ protein/d would ingest about $0.8 \mathrm{~g}$ tryptophan. A recent report on the safety of amino acids concluded that $3 \mathrm{~g}$ L-tryptophan/d can be taken without adverse effects (Anderson \& Raiten, 1992), but there is not enough information to estimate a safe level of intake for D-tryptophan.

In 1989, a new disease characterized by blood eosinophilia (raised number of a type of leucocyte) and myalgia (severe muscle pain), termed eosinophilia-myalgia syndrome, caused a number of deaths. Those suffering from this illness had all apparently consumed L-tryptophan supplements before the onset of the syndrome. Further research showed that this disease was linked to the Ltryptophan manufactured by one single company, leading investigators ultimately to conclude that the lethal reaction was probably triggered by an impurity resulting from the manufacturing process and not by the L-tryptophan itself (Mayeno \& Gleich, 1994). 


\subsection{Caffeine}

The potential toxicity of caffeine has been thoroughly investigated by public health organizations. A typical cup of coffee contains between 70 and $140 \mathrm{mg}$ caffeine. For a $70 \mathrm{~kg}$ person, this would amount to $1-2 \mathrm{mg}$ caffeine $/ \mathrm{kg}$ body weight, which would produce peak plasma levels of between 1 and $2 \mu \mathrm{g} / \mathrm{ml}$. The effects of caffeine differ between habitual and non-users of caffeine and depend on the timing of caffeine intake, i.e. whether taken as a single dose or spread over the day. The evidence suggests that adverse effects and toxicity of caffeine are negligible, even in newborns, when plasma concentrations remain below $20 \mu \mathrm{g} / \mathrm{ml}$. Thus, for adults, $250 \mathrm{mg} / \mathrm{d}$ (about 2.5 cups of coffee) should be a safe dose, which can be increased to $350 \mathrm{mg} / \mathrm{d}$ if only minor effects are considered. Acute toxicity begins when plasma concentrations reach $30-50 \mu \mathrm{g} / \mathrm{ml}$ (Stavric, 1988), and caffeine intake can be as high as $500 \mathrm{mg} / \mathrm{d}$ without any major side-effects (Debry, 1989). More research is needed to ascertain the long-term effects of habitual caffeine intake, in particular on hypertension and osteoporosis.

\subsection{Macronutrient substitutes and flavour enhancers}

The safety of the high-intensity sweeteners currently in the food supply has been a long-standing cause for public concern. However, these have been extensively evaluated and there is no substantive evidence that they pose a risk (Walker, 1995). As most fat substitutes are derived from nonsynthetic materials such as starch gums, soluble fibre, and food proteins, these are generally recognized as safe. The important exception would be SPE which, after detailed reviews addressing concerns regarding digestibility and impaired absorption of fat-soluble vitamins, won approval by the US Food and Drug Administration for limited use in commercial food products (Lindley, 1993). Most flavour enhancers such as MSG are generally consumed in very small quantities on a daily basis. Glutamic acid is a substance of minimal toxicity and an acceptable daily intake level is currently 'not specified' (World Health Organization, 1987).

\section{Hyperactivity}

\subsection{Overview}

Hyperactivity or, more precisely, attention-deficit/ hyperactivity disorder is a condition most often seen in children, and more often in boys than in girls (American Psychiatric Association, 1994). These children are often described by their mothers as 'overactive,' 'doesn't finish projects', 'fidgets', 'can't sit still at meals', 'doesn't stay with games', or 'talks too much' (Stewart, 1970). There are two popular hypotheses about the aetiology of hyperactivity, one relating hyperactivity to the consumption of sugar, the other to food additives.

\subsection{Hyperactivity and sugar}

Crook (1974) observed that when sucrose was eliminated from a hyperactive child's diet, behaviour improved, but the symptoms returned when sugar was reintroduced. Similarly,
Rapp (1978) eliminated various food items including sucrose from the diet of hyperactive children. In seven out of twenty-one cases, the parents reported that hyperactive behaviour increased as sugar was reinstated. Based on these and other case studies, sugar was concluded to be a major cause of hyperactivity. However, these studies have methodological problems. Removing sugar from a diet will change many aspects of the diet. The omission of control groups or the lack of a double-blind intervention makes it possible that expectations and suggestions, rather than sugar, are responsible for the behavioural changes.

Several correlational studies have also supported the idea that sugar plays a role in hyperactivity. Prinz et al. (1980) compared twenty-six hyperactive children with twenty-six controls for 'destructive-aggressive' behaviours and restlessness. In the hyperactive group they found a correlation between sugar intake (as estimated from a food diary of the previous week) and destructive-aggressive behaviours. A correlation between sugar intake and activity was also observed in the children in the control group. Wolraich et al. (1986) failed to find significant correlations between behaviour and sugar intake, although there was some evidence that a higher sugar:total energy ratio was associated with elevated activity, off-task behaviours and attention-shifts. When comparing pre-school boys who consumed the largest amounts of sugar with boys who consumed the least amounts in a vigilance test, Prinz \& Riddle (1986) found that the high sugar group was less able to sustain attention.

The majority of experimental studies do not support the idea that sugar consumption leads to an increase in activity or hyperactivity. A number of studies comparing a sucrose challenge with a placebo, usually saccharin or aspartame, did not find differences in diverse measures like activity (assessed by an actometer or by the Conners rating scale), impulsivity, or locomotion (Wolraich et al. 1985; Ferguson et al. 1986; Roshon \& Hagen, 1989). Behavioural differences following sugar $v$. placebo were not found even when children diagnosed with attention deficit disorder were investigated (Mahan et al. 1988; Wender \& Solanto, 1991), and some studies even found a decrease in activity levels after consumption of sucrose or glucose (Behar et al. 1984; Saravis et al. 1990). Even though a few studies report higher activity in children after high doses of sucrose (e.g. Rosen et al. 1988), the experimental evidence, taken altogether, does not support a causal association between sugar and activity. A reverse causality can also be envisaged: hyperactive children need more energy, and more sugar, than sedentary peers.

\subsection{Hyperactivity and food additives}

Feingold (1981) proposed that hyperactivity is due to an increased tendency of children to react to food additives such as artificial flavours, artificial colours, and preservatives. He eliminated these substances from a dietary regimen that came to be known as 'the Feingold diet'. Some support for the Feingold diet comes from an experiment with twenty hyperactive and twenty non-hyperactive children (Swanson \& Kinsbourne, 1980). All children were put on the Feingold diet for $5 \mathrm{~d}$. They received a capsule with 
either placebo or food dyes on days 4 and 5 and learning tasks were conducted on these days. The hyperactive, but not the non-hyperactive, children performed worse on this task after receiving food dyes as compared with placebo. However, as a relatively high dose of food dyes was used, this study design is not appropriate if the effects of food dyes in a normal diet are to be evaluated. In addition, it is not clear whether the experiment was conducted doubleblind or not (Logue, 1991). In an experimental study of twenty-two hyperactive children who were on the Feingold diet for a number of months, Weiss et al. (1980) gave average doses of food dyes on some days in a double-blind trial. In only two of the twenty-two children were the mothers able to detect effects of the dyes. In the other twenty, food dyes had no discernible effect. There is, to date, insufficient scientific evidence to support the Feingold hypothesis (Kolata, 1982; Logue, 1991).

\section{Critical assessment of the science base: identification of criteria}

The preceding survey of the scientific literature supports the view that, under certain circumstances, certain foods or food constituents can influence the cognitive and affective processes that drive human behaviour. Establishing a link between diet and behaviour is uniquely complex because the impetus for this sort of research often comes from outside the scientific community. To complicate matters, the news media typically jump in as de facto reviewers, overstating the importance of the latest findings, leaving the general public confused and frustrated when conflicting evidence subsequently appears.

Research exploring the putative link between diet and behaviour and/or related cognitive or emotional functioning (e.g. appetite and satiety, mood, cognition, performance, or pain perception) must conform to the rigorous scientific principles designed to guide researchers in the area of human behaviour as stringently as in any other scientific field. The following criteria should be kept in mind.

(1) Hypotheses must be based on validated, scientificallyestablished knowledge. Accordingly, a set of quantifiable independent and dependent variables must be integrated in research protocols designed to elucidate causal relationships.

(2) In interventional studies concerning food intake behaviour, statistically valid prospective data are required to confirm claims that certain foods or food constituents exert a stronger influence on appetite and satiety than could be expected on the basis of energy or nutrient content. This must be translated into measurable alterations in long-term intake and consequent effects on body weight.

(3) Laboratory studies must quantitatively demonstrate motivational effects on appetite and satiety. As artificial constraints are typically imposed, caution must be applied in generalizing results to naturalistic conditions. Studies of food intake motivation should clearly delineate the test conditions; that is, subject characteristics such as sex, age, BMI, and cognitive set, as well as other independent variables concerning the nature, amount, time course of ingestive events, and the ethnic, social, emotional, and physiological context of the experiment. Ideally, short-term laboratory studies will inspire hypotheses regarding long-term effects, which may then be tested in large field studies. Dose-response and temporal relationships are critical and should be specifically investigated.

(4) Whenever cognition, mood, or other aspects of performance are tested, validated ad hoc tests should be used in order to measure dependent effects, with special attention given to classic tests translated into foreign languages (and validated before they are used).

(5) The large variability seen in all aspects of human behaviour makes the establishment of clear treatment effects highly challenging. Nevertheless, no leniency should be tolerated in the use of stringent statistical significance criteria, which should be established from the outset.

(6) There should be clear evidence that agents designed to modify behaviour or psychological functions are safe, and this must apply to all potential user groups, particularly those over-consumers exposing themselves to the highest level of risk. Ingredients designed to modify diet composition must be demonstrated to produce favourable effects exclusively, with potential changes in food choices and the resulting nutrient content of habitual diet corresponding to nutritional recommendations. Constituents that modify appetite or satiety should not contribute to deterioration of nutritional balance. Potential maximum intake from dietary sources should be estimated.

(7) Four important caveats regarding data interpretation should be kept in mind: (a) data derived from animal models cannot replace human studies; (b) short-term response patterns do not necessarily reflect what will happen over the long term; a phenomenon happening over a few minutes or hours, no matter how impressive, should not be assumed to affect long-term motivation or behaviour; (c) results obtained from studies covering one type of subject or group should not be generalized $a$ priori to the general population; (d) functionality needs to be viewed in the context of food safety; the difference between dietary and pharmacological effects must be acknowledged.

(8) Whenever possible, biomarkers of nutritional manipulations should be investigated. Although a causeeffect relationship can be demonstrated at the behavioural level, the biological mechanisms responsible for the observed phenomena are worth elucidating since they allow a deeper understanding of the critical elements governing behaviour.

\section{Considerations for future research}

\subsection{Appetite and satiety}

With respect to macronutrient-specific appetite and macronutrient-specific satiety, additional research is needed to separate the effects of macronutrient composition of foods from effects related to their sensory characteristics (Johnson \& Vickers, 1993; Lloyd et al. 1994). The effects of 
food consumption can be compared by adjusting macronutrient composition while leaving sensory characteristics unchanged, and by comparing foods with the same macronutrient composition but different sensory characteristics. Modelling, with respect to estimation of macronutrientspecific compensation (see Beaton et al. 1992) might also be refined. It would be of interest to explore whether parameters representing macronutrient-specific satiety and sensory-specific satiety could be included in this model. Estimation of energy balance and body weight (Westerterp et al. 1995) has also been very useful. It might be possible to refine this model to take nutrient (as well as energy) balance into account. In this way, specific effects of macronutrients on energy intake and on body-weight regulation might be predicted.

\subsection{Macronutrient replacers}

With nutrient composition on commercial food labels increasingly common, consumers are generally familiar with the energy and macronutrient contents of the foods they choose. Future work needs to include food intake manipulations in subjects that are aware of the composition of the test foods they are served. Since responses can depend on whether the foods are given in solid or liquid form (Tournier \& LouisSylvestre, 1991), where possible test meals should be whole, conventional foods that people might normally consume. In addition, subjects' underlying motivation (e.g. passive avoidance of dietary energy, active dieting) vis-à-vis consumption of low-sugar and low-fat foods should also be taken into account (Blundell \& Green, 1996).

The effects of chronic use of energy-reduced foods on body weight, body composition, nutritional balance are only partially predictable on the basis of present knowledge. The variation typical of day-to-day ingestive behaviour confounds interpretation of short-term studies. Current understanding of the temporal pattern or time frame of energy and macronutrient compensation also remains incomplete. Further studies involving extended-time subject observation (weeks, months or years) are needed before the functional claims made for low-energy substitutes for fats and sugars can be adequately assessed.

\subsection{Palatability enhancers}

One question that remains unanswered is how MSG may influence long-term control of body weight and nutritional status. Objective measures of intake behaviour must be made over long periods of time, which again raises the issues of long-term control of food stimulation and monitoring of intake in free-living persons. Corollary effects on vitality, immune function, and other indices of general health in at-risk populations are also important issues that remain unexplored.

\subsection{Cognitive performance}

Many of the effects regarding performance on complex tasks and cognitive load are subject to modulating factors. These include time of day (diurnal rhythm), personality type (extroversion-introversion), level of arousal, load or difficulty of the task, and the nature of the task itself.

Future prospects for research on diet and cognitive performance should address several important issues including complex cognitive performance, the nature of the tasks and task load used, identification of subgroups susceptible to the effects of nutritional manipulations, interactions between subjective and objective measures of performance and the necessary methodological complexity required to assess these effects.

Cognitive performance can be affected by specific nutritional manipulations. However, the tests used have typically considered single components of cognitive function. The way in which these aspects of performance relate to compound tasks which require simultaneous use of multiple faculties, such as driving or operating machinery, is not clear. It is therefore important to demonstrate whether nutritional manipulations exert a net effect on complex cognitive performance in total or on specific aspects of a task with no detriment to the whole task.

\subsection{Pain perception}

More research is needed before the relationship between pain perception and food ingestion is elucidated. Of particular importance are the measurements of central as well as peripheral levels of opioids, the comparison of short- $v$. long-term effects, and comparative observations of normalweight $v$. obese individuals.

\subsection{Sensitive subgroups}

Specific subgroups of people may demonstrate sensitivity to nutritional interventions or have particular needs. Sensitivity has been shown in the young and the elderly, particularly when concomitant dietary deficiencies are present. Other research has identified dieters as a group that demonstrate decrements in certain aspects of performance (Green \& Rogers, 1995). A further subgroup likely to be susceptible to nutritional manipulations is those individuals operating under stressful challenges (e.g. long-distance truck drivers).

\subsection{Time-dependent effects}

A certain degree of methodological complexity is required to critically assess nutritional effects. One requirement is to control for effects and interactions with circadian rhythms. For example, carbohydrate may have different effects when presented at different times of day. Potential biphasic effects, whereby an intervention produces an initial positive effect on performance and a subsequent negative effect, may occur following the administration of certain substances, e.g. glucose or caffeine. However, biphasic effects vis-à-vis other manipulations have not been examined.

\section{References}

Aaron JI, Mela DJ \& Evans RE (1994) The influences of attitudes, beliefs, and label information on perceptions of reduced-fat spread. Appetite 22, 25-37. 
Acheson KJ, Campbell IT, Edholm OG, Miller DS \& Stock MJ (1980) The measurement of food and energy intake in man: an evaluation of some techniques. American Journal of Clinical Nutrition 33, 1147-1154.

Adams WR, Kiefer SW \& Badia-Elder N (1995) Tryptophan deficiency and alcohol consumption in rats as a model for disadvantaged human populations: a preliminary study. Medical Anthropologia 16, 175-191.

American Psychiatric Association (1994) Diagnostic and Statistical Manual of Mental Disorders, 4th ed. Washington, DC: American Psychiatric Association.

Anderson KJ \& Revelle W (1982) Impulsivity, caffeine and proof-reading: a test of the Easterbrook hypothesis. Journal of Experimental Psychology: Human Perception Performance 8, 614-624.

Anderson SA \& Raiten DJ (1992) Safety of Amino Acids Used as Dietary Supplements. Report prepared for the Food and Drug Administration.

Ballard-Barbash R, Graubard I, Schatzkin A \& Thompson FE (1996) Contribution of dieting to the inverse association between energy intake and body mass index. European Journal of Clinical Nutrition 50, 98-106.

Bartus RT, Dean RL, Beer B \& Lippa AS (1982) The cholinergic hypothesis of geriatric memory dysfunction. Science 216, 408-417.

Basiotis PP, Welsh SO, Cronin FJ, Kelsay JL \& Mertz W (1987) Number of days of food intake records required to estimate individual and group nutrient intakes with defined confidence. Journal of Nutrition 117, 1638-1641.

Beaton GH, Tarasuk V \& Anderson GH (1992) Estimation of possible impact of non caloric fat and carbohydrate substitutes on macronutrient intake in the human. Appetite 19, 87-103.

Beauchamp GK, Vazquez de Vaquera M \& Pearson PB (1987) Dietary status of human infants and their sensory responses to amino acid flavor. In Umami: A Basic Taste, pp. 125-138 [Y Kawamura and MT Kare, editors]. New York, NY: Marcel Dekker.

Behar D, Rapaport JL, Adams AA, Berg CK \& Cornblath M (1984) Sugar challenge testing with children considered behaviourally 'sugar reactive.' Nutrition and Behavior 1, 277-288.

Bellisle F, Dalix AM, Chappuis F, Rossi F, Fiquet P, Gaudin V, Assoun M \& Slama G (1996) Monosodium glutamate affects meal-time food selection in diabetic patients. Appetite 26, 267-276.

Bellisle F, Monneuse MO, Chabert M, Larue-Achagiotis C, Lanteaume MT \& Louis-Sylvestre J (1991) Monosodium glutamate as a palatability enhancer in the European diet. Physiology and Behavior 49, 869-873.

Bellisle F \& Perez C (1994) Low-energy substitutes for sugars and fats in the human diet: impact on nutritional regulation. Neuroscience and Biobehavioral Reviews 18, 197-205.

Benkelfat C, Ellenbogen MA, Palmour RM \& Young SN (1994) Mood-lowering effect of tryptophan depletion: enhanced susceptibility in young men at genetic risk for major affective disorders. Archives of General Psychiatry 51, 687-697.

Benton D (1992) Vitamin-mineral supplements and intelligence. Proceedings of the Nutrition Society 51, 295-302.

Benton D \& Owens D (1993) Blood glucose and human memory. Psychopharmacology 113, 83-88.

Benton D, Owens D \& Parker P (1994) Blood glucose, memory and attention. Neuropsychologia 115, 129.

Benton D \& Sargent J (1992) Breakfast, blood glucose and memory. Biological Psychology 33, 207-210.

Blass E \& Fitzgerald E (1988) Milk-induced analgesia and comforting in 10-day-old rats: opioid mediation. Pharmacology, Biochemistry and Behavior 29, 9-13.
Blass E, Fitzgerald E \& Kehoe P (1987) Interactions between sucrose, pain and isolation distress. Pharmacology, Biochemistry and Behavior 26, 483-489.

Blundell JE \& Burley VJ (1992) Evaluation of the satiating power of dietary fat in man. In Progress in Obesity Research, pp. 453-457 [Y Oomura, S Baba and T Shimazu, editors]. London: Libbey.

Blundell JE, Burley VJ, Rolls BJ \& Peters JC (1991) Simultaneous replication validates an effect of olestra on the pattern of eating. International Journal of Obesity 15, 9.

Blundell JE \& Green SM (1996) Effect of sucrose and sweeteners on appetite and energy intake. International Journal of Obesity 20, Suppl. 2, S12-S17.

Blundell JE \& Hill AJ (1986) Paradoxical effects of an intense sweetener (aspartame) on appetite. Lancet 1, 1092-1093.

Blundell JE, Lawton CL \& Hill AJ (1993) Mechanisms of appetite control and their abnormalities in obese patients. Hormonal Research 39, 72-76.

Booth DA (1991) Are low-calorie substitutes compensated? Appetite 17, 159-162.

Booth DA, Lee M \& McAleavey C (1976) Acquired sensory control of satiation in man. British Journal of Psychology 67, $137-147$

Caputo FA \& Mattes RD (1993) Human dietary responses to perceived manipulation of fat content in a midday meal. International Journal of Obesity 17, 237-240.

Carlson SE, Ford AJ, Werkman SH, Peeples JM \& Koo WWK (1996) Visual acuity and fatty acid status of term infants fed human milk and formulas with and without docosahexaenoate and arachidonate from egg yolk lecithin. Paediatric Research 5, 882-888.

Chandler AMK, Walker SP, Connolly K \& Grantham-McGregor SM (1995) School breakfast improves verbal fluency in undernourished Jamaican children. Journal of Nutrition 125, 894-900.

Chapelot D, Fricker J, Pasquet P \& Apfelbaum M (1993) Contribution of the cognitive factors in the response of restrained and non restrained eaters after a change in the fat content of the main course of lunch meal. International Journal of Obesity 17, 62 .

Christensen L, Krietsch K \& White B (1989) Development, crossvalidation, and assessment of the reliability of the Christensen Dietary Distress Inventory. Canadian Journal of Behavioral Science 21, 1-15.

Christensen L \& Redig C (1993) Effect of meal composition on mood. Behavioral Neuroscience 107, 346-353.

Colditz GA, Giovannucci E, Rimm EB, Stampfer MJ, Rosner B \& Speizer FE (1991) Alcohol intake in relation to diet and obesity among women and men. American Journal of Clinical Nutrition 54, 1701-1707.

Connors CK \& Blouin AG (1983) Nutritional effects on behaviour of children. Journal of Psychiatric Research 17, 198-201.

Crombie IK, Todman J, McNeill G, Florey C, Menzies IT \& Kennedy RA (1990) Effect of vitamin and mineral supplementation on verbal and non-verbal reasoning of schoolchildren. Lancet 311, 744-747.

Crook WG (1974) An alternative method of managing the hyperactive child. Paediatrics 5, 46-56.

Cueto S (1995) Cited in Pollitt E, Jacoby E \& Cueto S (1995) Breakfast prevents delays of memory functions. FASEB Journal 9, A483.

Deary IJ, Crawford JR, Hepburn D, Langan S, Blackmore L \& Frier BM (1993) Severe hypoglycaemia and intelligence in adult patients with insulin-treated diabetes. Diabetes 42, 341-344

de Castro JM (1987) Macronutrient relationships with meal patterns and mood in the spontaneous feeding behavior of humans. Physiology and Behavior 39, 561-569. 
de Castro JM \& de Castro ES (1989) Spontaneous meal patterns in humans: influence of the presence of other people. American Journal of Clinical Nutrition 50, 237-247.

de Graaf C, Hulshof T, Weststrate JA \& Hautvast JGA (1996) Non-absorbable fat (sucrose polyester) and the regulation of energy intake and weight. American Journal of Physiology 270, R1386-R1393.

de Graaf C, Hulshof T, Weststrate JA \& Jas P (1992) Short-term effects of different amounts of protein, fats and carbohydrates on satiety. American Journal of Clinical Nutrition 55, 33-38.

Debry G (1989) Le Café, sa Composition, sa Consommation, ses Incidences sur la Santé (Coffee: Composition, Intake and Health Considerations). Nancy: Centre de Nutrition Humaine.

Deijen JM, Heemstra ML \& Orlebeke JF (1989) Dietary effects on mood and performance. Journal of Psychiatric Research 23, 275-283.

Dickie NH \& Bender AE (1982) Breakfast and performance in schoolchildren. British Journal of Nutrition 48, 483-496.

Drewnowski A (1990) Dietary fats: perceptions and preferences. Journal of the American College of Nutrition 4, 431-435.

Drewnowski A, Kurth C, Holden-Wiltse J \& Saari J (1992) Food preferences in human obesity: carbohydrates versus fats. Appetite 18, 207-221.

Drewnowski A \& Schwartz M (1990) Invisible fats: sensory assessment of sugar/fat mixtures. Appetite 14, 203-217.

Dum J, Gramsch C \& Ferz A (1983) Activation of hypothalamic $\beta$-endorphin pools by reward induced by highly palatable food. Pharmacology, Biochemistry and Behavior 18, 443-447.

Duncan KH, Bacon JA \& Weinsier RL (1983) The effects of high and low energy density diets on satiety, energy intake and eating time of obese and non obese subjects. American Journal of Clinical Nutrition 46, 886-892.

Feingold BF (1981) Dietary management of behavior and learning disabilities. In Nutrition and Behavior [SA Miller, editor]. Philadelphia, PA: Franklin Institute.

Ferguson HB, Stoddart C \& Simeon PG (1986) Double blind challenge studies of behavioural and cognitive effects of sucrose-aspartame ingestion in normal children. Nutrition Reviews 44, Suppl., 144-150.

Fernstrom J (1994) The effect of dietary macronutrients on brain serotonin formation. In Appetite and Body Weight Regulation, pp. 51-62 [JD Fernstrom and GD Miller, editors]. Boca Raton, FL: CRC Press, Inc.

Fernstrom JD \& Wurtman RJ (1972) Brain serotonin content: physiological dependence on plasma tryptophan levels. Science 173, 149-151.

Fernstrom MH, Krowinski RL \& Kupfer DJ (1987) Appetite and food preference in depression: effects of imipramine treatment. Biological Psychiatry 22, 529-539.

Foltin RW, Kelly TH \& Fischman MW (1993) Ethanol as an energy source in humans: comparison with dextrose-containing beverages. Appetite 20, 95-110.

Fourest-Fontecave S, Adamson E, Lins PE, Ekblom B, Sendahl C \& Strand L (1987) Mental alertness in response to hypoglycaemia in normal man: the effect of 12 hours and 72 hours of fasting. Diabète et Métabolisme 13, 405-410.

Garner DM, Olmstead MP \& Polivy J (1983) Development and validation of a multidimensional eating disorders inventory for anorexia nervosa and bulimia. International Journal of Eating Disorders 2, 15-34.

Gonder-Frederick L, Hall JL, Vogt J, Cox DJ, Green J \& Gold PE (1987) Memory enhancement in elderly humans: effects of glucose ingestion. Physiology and Behavior 41, 503-504.

Goodwin GM, Fairburn CG \& Cowen PJ (1987) Dieting changes serotonergic function in women, not men: implications for the aetiology of anorexia nervosa? Psychological Medicine 17, $839-842$
Goodwin JS, Goodwin JM \& Garry PJ (1983) Association between nutritional status and cognitive functioning in a healthy elderly population. Journal of the American Medical Association 249, 2917-2921.

Green MW \& Rogers PJ (1995) Impaired cognitive functioning during spontaneous dieting. Psychological Medicine 25, 115-129.

Greenwood CE \& Winocur G (1990) Learning and memory impairment in rats fed a high saturated fat diet. Behavioral Neural Biology 53, 74-87.

Hall JL, Gonder-Frederick LA, Chewning WW, Silveira J \& Gold PE (1989) Glucose enhancement of performance on memory tests in young and aged humans. Neuropsychologia 27, 1129-1138.

Herman CP \& Polivy J (1980) Restrained eating. In Obesity, pp. 208-225 [AJ Stunkard, editor]. Philadelphia, PA: Saunders.

Herold KC, Polonsky KS, Cohen RM, Levy J \& Douglas F (1985) Variable deterioration in cortical function during insulininduced hypoglycaemia. Diabetes 34, 677-685.

Hill AJ \& Blundell JE (1988) Role of amino acids in appetite control in man. In Amino Acids in Health and Disease, pp. 239-248 [G Huether, editor]. Berlin: Springer Verlag.

Hindmarch I, Kerr JS \& Sherwood N (1991) The effects of alcohol and other drugs on psychomotor performance and cognitive function. Alcohol and Alcoholism 26, 71-79.

Holmes CS, Koepke KM \& Thompson RG (1986) Simple versus complex impairment at three blood glucose levels. Psychoneuroendocrinology 11, 353-357.

Hulshof T, de Graaf C \& Weststrate JA (1995) Short term satiating effect of the fat replacer sucrose polyester (SPE) in man. British Journal of Nutrition 74, 569-585.

James JE (1991) Caffeine and Health. London: Academic Press.

Jarvis MJ (1993) Does caffeine intake enhance absolute levels of cognitive performance? Psychopharmacology 110, 45-52.

Johnson J \& Vickers Z (1993) Effects of flavor and macronutrient composition of food servings on liking, hunger and subsequent intake. Appetite 21, 25-39.

Kanarek RB \& Swinney D (1990) Effects of food snacks on cognitive performance in male college students. Appetite 14, 15-27.

Kant AK, Ballard-Barbash R \& Schatzkin A (1995) Evening eating and its relation to self-reported body weight and nutrient intake in women, CSFII 1985-86. Journal of the American College of Nutrition 14, 358-363.

Kaye WH, Pickar D, Naber D \& Ebert MH (1982) Cerebrospinal fluid opioid activity in anorexia nervosa. Psychiatry 139 , 643-645.

Kelly TH, Foltin RW, Rolls BJ \& Fischman MW (1994) Effect of meal macronutrient and energy content on human performance. Appetite 23, 97-111.

Kendall A, Levitsky DA, Strupp BJ \& Lissner L (1991) Weight loss on a low-fat diet: consequence of the impression of the control of food intake in humans. American Journal of Clinical Nutrition 53, 1124-1129.

Kolata G (1982) Consensus on diets and hyperactivity. Science 215, 958.

Kruesi MJP \& Rapoport JL (1986) Diet and human behavior: how much do they affect each other? Annual Review of Nutrition 6 , 113-130.

Langan SJ, Deary IJ, Hepburn DA \& Frier BM (1991) Cumulative cognitive impairment following recurrent severe hypoglycaemia in adult patients with insulin-treated diabetes mellitus. Diabetalogia 34, 337-344.

Lapp JE (1981) Effects of glycemic alterations and noun imagery on the learning of paired associates. Journal of Learning Disabilities 14, 35-38.

Lieberman H, Corkin S, Spring B, Growdon JH \& Wurtman RJ 
(1983) Mood, performance and sensitivity: changes induced by food constituents. Journal of Psychiatric Research 17, $135-145$.

Lieberman HR, Spring B \& Garfield GS (1986) The behavioral effects of food constituents: strategies used in studies of amino acids, protein, carbohydrates and caffeine. Nutrition Reviews $\mathbf{4 4}$, Suppl., 61-69.

Lindley MG (1993) Fat replacer ingredients and the markets for fat-reduced foods. In Low-Calorie Foods and Food Ingredients, pp. 77-105 [R Kahn, editor]. London: Blackie Academic and Professional.

Lipton MA \& Kane FJ (1983) Psychiatry. In Nutritional Support of Medical Practice, 2nd ed, pp. 562-580 [HA Scheider, CE Anderson and D Coursin, editors]. Philadelphia, PA: Harper \& Row.

Lissner L, Levitsky DA, Strupp BJ, Kalkwarf HJ \& Roe DA (1987) Dietary fat and the regulation of energy intake in human subjects. American Journal of Clinical Nutrition 46, 886-892.

Lloyd HM, Green MW \& Rogers PJ (1994) Mood and cognitive performance effects of isocaloric lunches differing in fat and carbohydrate content. Physiology and Behavior 56, 51-57.

Lloyd HM \& Rogers PJ (1995) Mood and cognitive performance improved by low dose of alcohol administered double blind. Appetite 24, 280.

Lloyd HM, Rogers PJ \& Hedderley DI (1996) Acute effects on mood and cognitive performance of breakfasts differing in fat and carbohydrate content. Appetite 27, 151-164.

Logue AW (1991) The Psychology of Eating and Drinking. An Introduction, 2nd ed. New York, NY: W.H. Freeman.

Louis-Sylvestre J, Tournier A, Verger P, Chabert M \& Delorme B (1987) Learned caloric adjustment of human intake. Appetite 12 , 95-103.

Macdiarmid RI \& Hetherington MM (1995) Mood modulation by food: an exploration of affect and cravings in 'chocolate addicts'. British Journal of Psychology 34, 129-138.

McGivern RF \& Berntson GG (1980) Mediation of diurnal fluctuations in pain sensitivity in the rat by food intake patterns: reversal by naloxone. Science $\mathbf{2 1 0}, 210-211$.

McNair PM, Lorr M \& Dropplemen LF (1971) Profile of Mood States Manual. San Diego, CA: Educational and Industrial Testing Service.

Mahan LK, Chase M, Furukawa CT, Sulzbacher S, Shapiroo GG, Pierson W \& Bierman CW (1988) Sugar 'allergy' and children's behaviour. Annals of Allergy 61, 453-458.

Manning CA, Hall JL \& Gold PE (1990) Glucose effects on memory and other neuropsychological tests in elderly humans. Psychological Science 1, 307-311.

Martin LJ, Su W, Jones PJ, Lockwood GA, Tritchler DL \& Boyd NF (1996) Comparison of energy intakes determined by food records and doubly labeled water in women participating in a dietary-intervention trial. American Journal of Clinical Nutrition 63, 483-490.

Matsumura M, Fukuda N, Saito S \& Mori H (1982) Effect of a test meal, duodenal acidification, and tetragastrin on the plasma concentration of $\beta$-endorphin-like immunoreactivity in man. Regulatory Peptides 4, 173-181.

Mayeno AN \& Gleich DJ (1994) Eosinophilia-myalgia syndrome and tryptophan production: a cautionary tale. Tibtech 12 , $346-352$.

Melchior JC, Fantino M, Colas-Linhart N, Rigaud D, Petiet A, Laforest MD, Fumeron F \& Apfelbaum M (1991) Lack of plasmatic beta-endorphin response to a gastronomic meal in healthy humans. Physiology and Behavior 49, 1217-1221.

Mercer ME \& Holder MD (1997) Antinociceptive effects of palatable sweet ingesta on human responsivity to pressure pain. Physiology and Behavior 61, 311-318.

Michener W \& Rozin P (1994) Pharmacological versus sensory factors in the satiation of chocolate craving. Physiology and Behavior 56, 419-422.

Michaud C, Musse N, Nicolas JP \& Méjean L (1991) Effects of breakfast-size on short-term memory, concentration, mood and blood glucose. Journal of Adolescent Health 12, 53-57.

Milgram GG (1990) The Facts About Drinking: Coping With Alcohol Use, Abuse, and Excessive Drinking. New York, NY: Consumers Union.

Mitchell PJ \& Redman JR (1992) Effects of caffeine, time of day and user history on study-related performance. Psychopharmacology 109, $121-126$.

Nehlig A, Daval J-L \& Debry G (1992) Caffeine and the central nervous system: mechanisms of action, biochemical, metabolic and psychostimulant effects. Brain Research Reviews 17, 139-170.

Nelson M (1992) Vitamin and mineral supplementation and academic performance in schoolchildren. Proceedings of the Nutrition Society 51, 303-313.

Nelson M, Naismith DJ, Burley V, Gatenby SJ \& Geddes N (1990) Nutrient intakes, vitamin-mineral supplementation and intelligence in British schoolchildren. British Journal of Nutrition 64, $13-22$.

Owens DS \& Benton D (1994) The impact of raising blood glucose on reaction times. Neuropsychobiology 30, 106-113.

Perez C, Dalix AM, Guy-Grand B \& Bellisle F (1994) Human responses to five concentrations of sucrose in a dairy product: immediate and delayed palatability effects. Appetite 23, 165-178.

Pollitt E, Leibel RL \& Greenfield D (1981) Brief fasting, stress and cognition in children. American Journal of Clinical Nutrition 34, 1526-1533.

Pollitt E, Lewis NL, Garza C \& Shulman RJ (1983) Fasting and cognitive function. Journal of Psychiatric Research 17, 169-174.

Prewitt TE, Schmeisser D, Bowen PE, Aye P, Dolecek TA, Langenberg P, Cole T \& Brace L (1991) Changes in body weight, body composition, and energy intake in women fed high- and low-fat diets. American Journal of Clinical Nutrition 54, 304-310.

Prinz RJ \& Riddle DB (1986) Association between nutrition and behaviour. Nutrition Reviews 44, Suppl., 151-158.

Prinz RJ, Roberts WA \& Hantman E (1980) Dietary correlates of hyperactive behaviour in children. Journal of Consulting Clinical Psychology 47, 760-769.

Priola RD \& Lieber CS (1972) Energy cost of the metabolism of drugs, including ethanol. Pharmacology 7, 185-196.

Ramzan I, Wong BK \& Corcoran GB (1993) Pain sensitivity in dietary-induced obese rats. Physiology and Behavior 54, 433-435.

Rapp DJ (1978) Does diet affect hyperactivity? Learning Disabilities 11, 383-389.

Reid M \& Hammersley R (1995) Effect of carbohydrate intake on subsequent food intake and mood state. Physiology and Behavior 8, 421-427.

Richardson NJ, Rogers PJ, Elliman NA \& O’Dell RJ (1995) Mood and performance effects of caffeine in relation to acute and chronic caffeine deprivation. Pharmacology, Biochemistry and Behavior 52, 313-320.

Rissanen A, Sarlio-Lahteenkorva S, Alfthan G, Gref CG, Keso L \& Salaspuro M (1987) Employed problem drinkers: a nutritional risk group? American Journal of Clinical Nutrition 45, $456-461$.

Roane DS \& Martin RJ (1990) Continuous sucrose feeding decreases pain threshold and increases morphine potency. Pharmacology Biochemistry and Behavior 35, 225-229.

Rodin J \& Slochower J (1976) Externality in the nonobese: effects of environmental responsiveness on weight. Journal of Personality and Social Psychology 33, 338-344. 
Rogers PJ (1995) Food, mood and appetite. Nutrition Research Reviews 8, 243-269.

Rogers PJ, Richardson NJ \& Dernoncourt C (1995) Caffeine use: is there a net benefit for mood and psychomotor performance? Neuropsychobiology 31, 195-199.

Rolls BJ (1991) Effects of intense sweeteners on hunger, food intake, and body weight: a review. American Journal of Clinical Nutrition 53, 872-878.

Rolls BJ \& Hammer VA (1995) Fat, carbohydrate, and the regulation of energy intake. American Journal of Clinical Nutrition 62, 1086S-1095S.

Rolls BJ \& Hetherington M (1990) A behavior scientist's perspectives on the study of diet and behavior. In Diet and Behavior, pp. 209-227 [NA Krasnegor, GD Miller and AP Simopoumos, editors]. London: Springer-Verlag.

Rolls BJ, Hetherington M \& Burley VJ (1988) The specificity of satiety: the influence of different amounts of protein, fats and carbohydrate on satiety. Physiology and Behavior 43, 45-53.

Rolls BJ, Kim-Harris S, Fischmann MW, Foltin RW, Moran TH \& Stoner SA (1994) Satiety after preloads with different amounts of fat and carbohydrate: implications for obesity. American Journal of Clinical Nutrition 60, 476-487.

Rolls BJ, Pirraglia PA, Jones MB \& Peters JC (1992) Effects of olestra, a noncaloric fat substitute, on daily energy and fat intakes in lean men. American Journal of Clinical Nutrition 56, 84-92.

Rolls ET \& Rolls JH (1997) Olfactory sensory-specific satiety in humans. Physiology and Behavior 61, 461-473.

Rosen LA, Booth SR, Bender ME, McGrath ML, Sorrel S \& Drabman R (1988) Effects of sugar (sucrose) on children's behavior. Journal of Consulting Clinical Psychology 56, $583-589$.

Rosenthal NE, Genhart MJ, Caballero B, Jacobsen FM, Skwerer RG, Coursey RD, Rogers S \& Spring BJ (1989) Psychobiological effects of carbohydrate- and protein-rich meals in patients with seasonal affective disorder and normal controls. Biological Psychiatry 25, 1029-1040.

Rosenthal NE \& Hefferman MM (1986) Bulimia, carbohydrate craving, and depression: a central connection. In Nutrition and the Brain, vol. 7, pp. 139-166 [RJ Wurtman and JJ Wurtman, editors]. New York, NY: Raven Press.

Roshon MS \& Hagen RL (1989) Sugar consumption, locomotion, task orientation, and learning in preschool children. Journal of Abnormal Child Psychology 17, 349-357.

Rumpler WV, Rhodes DG, Baer DJ, Conway JM \& Seale JL (1996) Energy value of moderate alcohol consumption by humans investigated. The effects of an equal-energetic substitution of ethanol for dietary carbohydrate in high- and low-fat diets on energy expenditure and body composition. American Journal of Clinical Nutrition 64, 108-114.

Saravis S, Schachar R, Zlotkin S, Leiter LA \& Anderson GH (1990) Aspartame: effects on learning, behaviour and mood. Paediatrics 86, 75-80.

Schlundt DG, Virts KL, Sbrocco T, Pope-Cordle J \& Hill JO (1993) A sequential behavioral analysis of craving sweets in obese women. Addictive Behavior 18, 67-80.

Schrauwen LPAJ, van Marken Lichtenbelt WD, Thimister EJEM \& Westerterp KR (1995) Feeding subjects at energy balance in a respiration chamber. International Journal of Obesity 19, 82.

Schweiger U, Laessle RG, Kittl S, Dickhaut B, Schweiger M \& Pirke KM (1986) Macronutrient intake, plasma large neutral amino acids and mood during weight-reducing diets. Journal of Neural Transplantation 67, 77-83.

Shetty PS, Prentice AM, Goldberg GR, Murgatroyd PR, McKenna APM, Stubbs RJ \& Volschenk PA (1994) Alterations in fuel selection and voluntary food intake in response to iso-energetic manipulation of glycogen stores in man. American Journal of Clinical Nutrition 60, 534-543.
Silverman K, Evans SM, Strain EC \& Griffiths RR (1992) Withdrawal syndrome after double-blind cessation of caffeine consumption. New England Journal of Medicine 327, 1109-1114.

Simeon T \& Grantham-McGregor S (1989) Effects of missing breakfast on the cognitive functions of school children with differing nutritional status. American Journal of Clinical Nutrition 49, 646-653.

Sjødin A, Andersson A, Hogberg J \& Westerterp K (1994) Energy balance in cross country skiers. Medicine and Science in Sports and Exercise 26, 720-724.

Smith AP \& Kendrick AM (1992) Meals and performance. In Handbook of Human Performance, vol. 2, Health and Performance, pp. 2-23 [AP Smith and DM Jones, editors]. London: Academic Press.

Smith A, Kendrick A \& Maben AL (1992) Use and effects of food and drinks in relation to daily thythms of mood and cognitive performance. Effects of caffeine, lunch and alcohol on human performance, mood and cardiovascular function. Proceedings of the Nutrition Society 51, 325-333.

Smith AP, Kendrick A, Maben A \& Salmon J (1994a) Effects of breakfast and caffeine on cognitive performance, mood and cardiovascular functioning. Appetite 22, 39-55.

Smith AP, Maben A \& Brockman P (1994b) Effects of evening meals and caffeine on cognitive performance, mood and cardiovascular functioning. Appetite 22, 57-65.

Smith AP \& Miles C (1986a) Effects of lunch on selective and sustained attention. Neuropsychobiology 16, 117-120.

Smith AP \& Miles C (1986b) The effects of lunch on cognitive vigilance tasks. Ergonomics 29, 1251-1261.

Smith AP \& Miles C (1987) The combined effects of occupational health hazards: an experimental investigation of the effects of noise, nightwork and meals. Internal Archives of Occupational Environmental Health 59, 83-89.

Smith AP, Rusted JM, Savory M, Eaton-Williams P \& Hall SR (1991) The effects of caffeine, impulsivity and time of day on performance, mood, and cardiovascular function. Journal of Psychopharmacology 5, 120-128.

Sonko BJ, Prentice AM, Murgatroyd PR, Goldberg GR, van de Ven MLHM \& Coward WA (1994) Effect of alcohol on post-meal fat storage. American Journal of Clinical Nutrition 59, 619-625.

Spitzer L \& Rodin J (1981) Human eating behavior: a critical review of studies in normal and overweight individuals. Appetite 2, 293-329.

Spring B, Chiodo J \& Bowen DJ (1987) Carbohydrates, tryptophan, and behavior: a methodological review. Psychological Bulletin 102, 234-256.

Spring B, Maller O, Wurtman J, Digman L \& Gozolino L (1983) Effects of protein and carbohydrate meals on mood and performance: interactions with sex and age. Journal of Psychiatric Research 17, 155-167.

Stavric B (1988) Methylxanthines: toxicity to humans. 2. Caffeine. Food and Chemical Toxicology 26, 645-662.

Steinberg LA, O'Connell NC, Hatch TF, Picciano MF \& Birch LL (1992) Tryptophan intake influences infants' sleep latency. Journal of Nutrition 122, 1781-1791.

Stewart MA (1970) Hyperactive children. Scientific American 222, 94-99.

Stubbs RJ (1995) Macronutrient effects on appetite. International Journal of Obesity 19, S11-S19.

Stunkard AJ \& Messick S (1985) The three factor eating questionnaire to measure dietary restraint, disinhibition and hunger. Journal of Psychosomatic Research 29, 71-83.

Swanson JM \& Kinsbourne M (1980) Food dyes impair performance of hyperactive children on a laboratory learning test. Science 207, 1485-1487. 
Tamerin JS \& Mendelson JH (1969) The psychodynamics of chronic inebriation; observation of alcoholics during the process of drinking in an experimental group setting. American Journal of Psychiatry 125, 886-889.

Teff KL, Young SN, Marchand L \& Botez MI (1989) Acute effect of protein or carbohydrate breakfasts on human cerebrospinal fluid monoamine precursor and metabolite levels. Journal of Neurochemistry 52, 235-241.

Thayer RE (1987) Energy, tiredness, and tension effects of a sugar snack versus modest exercise. Journal of Personality and Social Psychology 52, 119-125.

Tournier A \& Louis-Sylvestre J (1991) Effect of the physical state of a food on subsequent intake in human subjects. Appetite 16, $17-24$

Tremblay A \& Saint-Pierre S (1996) The hyperphagic effect of a high-fat diet and alcohol intake persists after control for energy density. American Journal of Clinical Nutrition 63, 479-482.

Tuttle WW, Daum K, Imig CJ, Randall S \& Schumacher MT (1952) Effect of omitting breakfast on the physiologic response of the aged. Journal of the American Dietetic Association 28, 117-120.

Tuttle WW, Daum K, Larsen R, Salzano J \& Roloff L (1954) Effect on schoolboys of omitting breakfast: physiologic responses, attitudes and scholastic attainments. Journal of the American Dietetic Association 30, 674-677.

Tuttle WW, Daum K, Myers L \& Martin C (1950) Effects of omitting breakfast on the physiologic response of men. Journal of the American Dietetic Association 26, 332-335.

Vaisman N, Voet H, Akivis A \& Vakil E (1996) Effect of breakfast timing on the cognitive functions of elementary school students. Archives of Pediatric and Adolescent Medicine 150, 1089-1092.

Verboeket van de Venne WPHG \& Westerterp KR (1991) Influence of the feeding frequency on nutrient utilization in man: consequences for energy metabolism. European Journal of Clinical Nutrition 45, 161-169.

Walker R (1995) The safety of light foods. In Light Foods, pp. 87-94 [PD Leathwood, J Louis-Sylvestre and J-P Mareschi, editors]. Brussels: ILSI Press.

Wallin MS \& Rissanen AN (1994) Food and mood: relationship between food, serotonin, and affective disorders. Acta Psychiatrica Scandinavica 377, 36-70.

Waterhouse J, Minors D, Atkinson G \& Benton D (1997) Chronobiology and mealtimes: internal and external factors. British Journal of Nutrition 77, Suppl. 1, S29-S38.

Weiss B, Williams JH, Margen S, Abrams B, Caan B, Citron LJ, Cox C, McKibben J, Ogar D \& Schulz S (1980) Behavioral responses to artificial food colors. Science $207,1487-1489$.

Wells AS \& Read NW (1996) Influences of fat, energy and time of day on mood and performance. Physiology and Behavior 59, 1069-1076.

Wender EH \& Solanto MV (1991) Effects of sugar on aggressive and inattentive behaviour in children with attention deficit disorder upon identification of targets in a non-search task. Perceptual Psychophysiology 16, 143-149.

Westerterp KR, Donkers HHLM, Fredrix EWHM \& Boekhoudt P (1995) Energy intake, physical activity and body weight: a simulation model. British Journal of Nutrition $\mathbf{7 3}$, $337-347$.

Westerterp KR, Verboeket van de Venne WPHG, Meijer GAL \& ten Hoor F (1992) Self reported intake as a measure for energy intake, a validation against doubly labelled water. In Obesity in Europe 91, pp. 17-22 [G Ailhaud, B Guy-Grand, M Lafontan and D Ricquier, editors]. London: John Libbey.

Westerterp KR, Verboeket-van de Venne WPHG, WesterterpPlantenga MS, Velthuis-te Wierik EJM, de Graaf C \&
Westrate JA (1996) Dietary fat and body fat: an intervention study. International Journal of Obesity 20, 1022-1026.

Westerterp-Plantenga MS, Ijedema MJW \& Wijckmans-Duijsens NEG (1996a) The role of macronutrient selection in determining patterns of food intake in obese and nonobese women. European Journal of Clinical Nutrition $\mathbf{5 0}$, 580-591.

Westerterp-Plantenga MS, Pasman WJ, Ijedema MJW \& Wijckmans-Duijsens NEG (1996b) Energy intake adaptation of food intake to extreme energy densities of food by obese and non-obese women. European Journal of Clinical Nutrition 50, 401-407.

Westerterp-Plantenga MS, Wijckmans-Duijsens NEG \& ten Hoor F (1994) Food intake in the daily environment after energyreduced lunch related to habitual meal frequency. Appetite $\mathbf{2 2}$, 173-182.

Westerterp-Plantenga MS, Wijckmans-Duijsens NEG, ten Hoor F \& Weststrate JA (1997a) Effect of replacement of fat by nonabsorbable fat (Sucrose Polyester) in meals or snacks as a function of dietary restraint. Physiology and Behavior 61, 939-947.

Westerterp-Plantenga MS, Wijckmans-Duijsens NEG, Verboeketvan de Venne WPHG, de Graaf C, Weststrate JA \& van het Hof KH (1997b) Diet-induced thermogenesis and satiety in humans, after full fat and reduced fat meals. Physiology and Behavior 61, 343-349.

World Health Organization (1987) Evaluation of Certain Food Additives and Contaminants. Technical Report Series no. 759. Geneva: WHO.

Wolraich M, Milich R, Stumbo P \& Schutz F (1985) Effects of sucrose ingestion on the behaviour of hyperactive boys. Journal of Pediatrics 106, 675-682.

Wolraich M, Stumbo P, Milich R, Chenard C \& Schultz F (1986) Dietary characteristics of hyperactive and control boys and their behavioural correlates. Journal of the American Dietetic Association 86, 500-504.

Wurtman JJ (1984) The involvement of brain serotonin in excessive carbohydrate snacking by obese carbohydrate cravers. Journal of the American Dietetic Association 84, 1004-1007.

Wurtman JJ, Brzezinski A, Wurtman RJ \& Laferrere B (1989) Effect of nutrient intake on premenstrual depression. American Journal of Obstetrics and Gynecology 161, 1228-1235.

Wyon DP, Abrahamsson L, Järtelius M \& Fletcher RJ (1997) An experimental study of the effects of energy intake at breakfast on the test performance of 10-year-old children in school. International Journal of Food Sciences and Nutrition 48, 5-12.

Yamaguchi $S$ (1987) Fundamental properties of Umami in human taste perception. In Umami: A Basic Taste, pp.41-73 [Y Kawamura and MT Kare, editors]. New York, NY: Marcel Dekker.

Yamaguchi S (1991) Basic properties of Umami and effects on humans. Physiology and Behavior 49, 833-841.

Young SN (1991) Some effects of dietary components (amino acids, carbohydrate, folic acid) on brain serotonin synthesis, mood, and behaviour. Canadian Journal of Physiology and Pharmacology 69, 893-903.

Young SN (1993) The use of diet and dietary compounds in the study of factors controlling affect in humans. Journal of Psychiatric Neuroscience 18, 235-244.

Young SN, Smith SE, Pihl RO \& Ervin FR (1985) Tryptophan depletion causes a rapid lowering of mood in normal males. Psychopharmacology 87, 173-177. 